\title{
Recent Progress in Vascular Aging: Mechanisms and Its Role in Age-related Diseases
}

\author{
Xianglai Xu' ${ }^{1,2, *}$, Brian Wang ${ }^{2}$, Changhong Ren ${ }^{2,4}$, Jiangnan $\mathrm{Hu}^{2}$, David A. Greenberg ${ }^{5}$, \\ Tianxiang Chen ${ }^{6}$, Liping Xie ${ }^{3,}$, Kunlin Jin², * \\ ${ }^{1}$ Zhongshan Hospital, Fudan University, Shanghai 200032, China. \\ ${ }^{2}$ Department of Pharmacology and Neuroscience, University of North Texas Health Science Center at Fort Worth, \\ TX 76107, USA. \\ ${ }^{3}$ Department of Urology, the First Affiliated Hospital, Zhejiang University, Zhejiang Province, China. \\ ${ }^{4}$ Institute of Hypoxia Medicine, Xuanwu Hospital, Capital Medical University. Beijing, China. \\ ${ }^{5}$ Buck Institute for Research on Aging, Novato, CA 94945, USA. \\ ${ }^{6}$ Department of Thoracic Surgery, Shanghai Chest Hospital, Shanghai Jiaotong University, Shanghai, China.
}

[Received December 7, 2016; Revised April 15, 2017; Accepted May 7, 2017]

\begin{abstract}
As with many age-related diseases including vascular dysfunction, age is considered an independent and crucial risk factor. Complicated alterations of structure and function in the vasculature are linked with aging hence, understanding the underlying mechanisms of age-induced vascular pathophysiological changes holds possibilities for developing clinical diagnostic methods and new therapeutic strategies. Here, we discuss the underlying molecular mediators that could be involved in vascular aging, e.g., the renin-angiotensin system and pro-inflammatory factors, metalloproteinases, calpain-1, monocyte chemoattractant protein-1 (MCP-1) and TGF $\beta-1$ as well as the potential roles of testosterone and estrogen. We then relate all of these to clinical manifestations such as vascular dementia and stroke in addition to reviewing the existing clinical measurements and potential interventions for age-related vascular dysfunction.
\end{abstract}

Key words: vascular aging, stroke, dementia, arterial stiffness, endothelial dysfunction

\section{Introduction}

Among aging-related diseases, age-specific mortality rates from cardiovascular diseases (CVDs) rise exponentially from more than $40 \%$ of all deaths at age 65 74 to almost $60 \%$ in the 85 and over age group to become the leading cause of death [1]. The Global Burden of Disease Study reported that 15.6 million people died from CVDs worldwide in 2010 , accounting for $29.6 \%$ of all deaths, or twice as many as the deaths from cancers [2]. This proportion is even higher in Europe, where CVDs are responsible for nearly half of all deaths [3].
Cerebrovascular diseases, if considered separately, accounts for $12 \%$ of all deaths in Europe annually. Moreover, cerebrovascular diseases such as vascular cognitive impairment dramatically decrease the quality of life, even though they do not cause death directly. Therefore, aging research is of great importance, especially in the context of cerebrovascular diseases, from bench to bedside. Understanding the mechanisms underlying age-induced vascular pathophysiological alterations also holds possibilities for developing clinical diagnostic methods and new therapeutic strategies.

The current review will discuss the molecular

*Correspondence should be addressed to: Dr. Xianglai Xu, Zhongshan Hospital, Fudan University, Shanghai, China. Email: xuxianglai@163.com; Dr. Liping Xie, the First Affiliated Hospital, Zhejiang University, China. Email: xielp@zjuem.zju.edu.cn; Dr. Kunlin Jin, University of North Texas Health Science Center, Fort Worth, TX 76107, USA. Email: Kunlin.Jin@,unthsc.edu

Copyright: () 2017. This is an open-access article distributed under the terms of the Creative Commons Attribution License (CC BY 4.0), which permits unrestricted use, distribution, and reproduction in any medium, provided the original author and source are credited. 
alterations of aging vessels and their associated clinical conditions, especially in cerebral vessel-related diseases. We will also address possible therapeutic approaches, which may potentially improve cardiovascular and cerebrovascular health in the aged.

\section{Signaling pathways participating in vascular aging}

\section{Renin/angiotensin system and pro-inflammatory factors}

The renin/angiotensin system (RAS) is of great importance in vascular biology, mediating normal vessel function and participating in pathogenesis. Ang II acts through the AT1 and AT2 receptors and Ang II signaling plays a crucial role in the vascular remodeling process $[4$, 5].

The majority of Ang II is the product of Ang I cleavage by angiotensin converting enzyme (ACE). The expression and activity of the angiotensin-converting enzyme-1 (ACE-1) significantly increase in both ECs and VSMCs during aging [6-8]. Chymase, an alternative angiotensin convertase, also shows increased expression within the aging arterial wall $[7,8]$. Consequently, the cleaved product, Ang II, is markedly upregulated in rats, monkeys and humans [7-9]. AT1 levels also increase within the aged arterial wall. In contrast, the expression of ACE2 decreases with age, reducing its inhibitory effects on the RAS, which might lead to higher expression levels of Ang II and more Ang II-related vascular alteration [10]. Thus, the net activity of the RAS is increased in the elderly. Under normal physiological conditions, the RAS is well regulated. However, increased activity is associated with several vascular dysfunctions (Fig. 1) [11, 12].

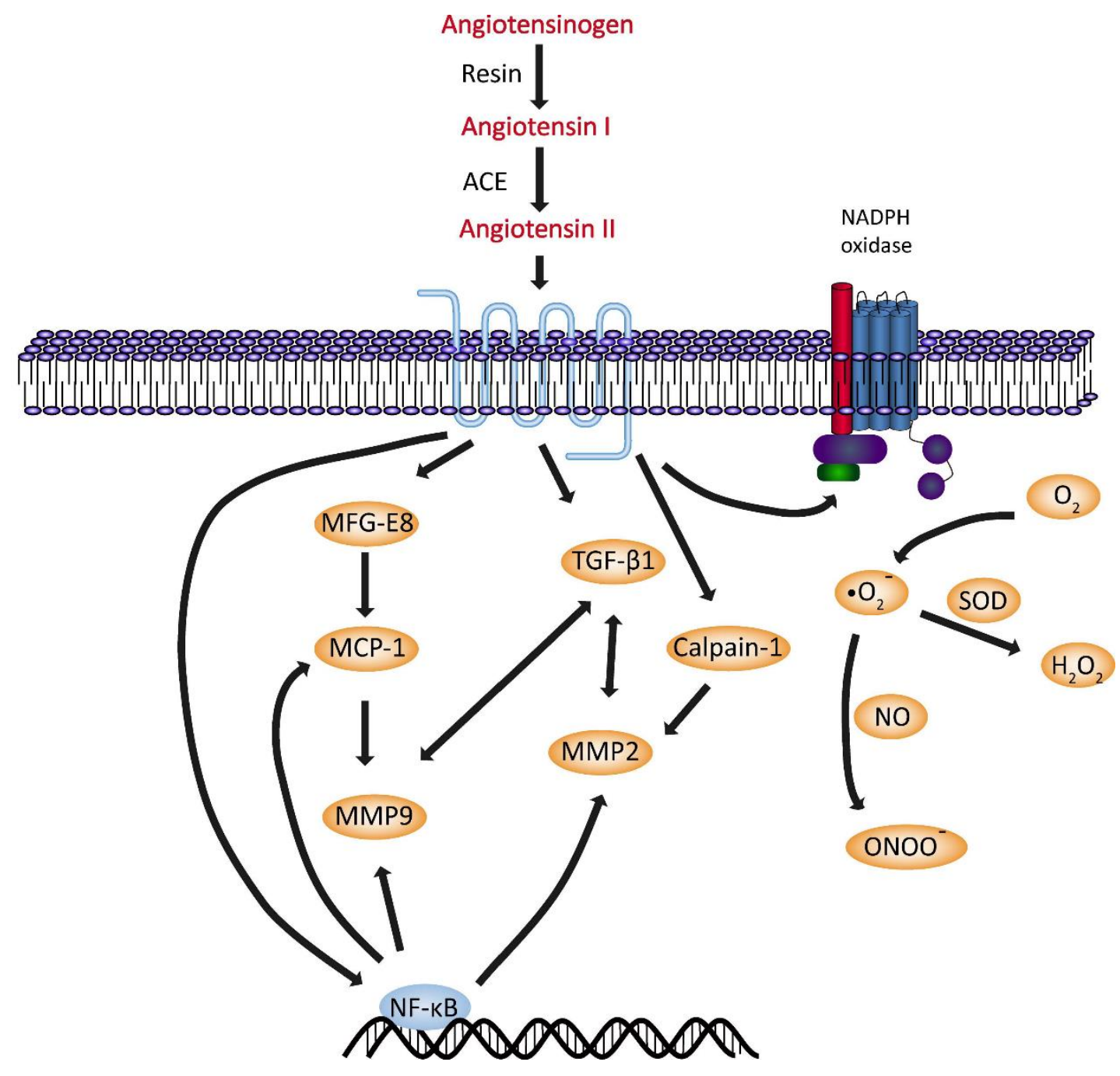

Figure 1. Angiotensin II signaling pathway underlying vascular aging. 
Ang II is an inflammatory trigger that increases the activation of inflammatory factors in the arterial wall with advancing age. It activates nuclear transcription factorkappa B (NF-kB), a key inflammatory marker, through the AT1 and AT2 receptors and then initiates an inflammatory signaling loop [13]. Induction of NF- $\mathrm{BB}$ upregulates the activities of MMP-2/-9, calpain-1, MCP1 , TGF- $\beta 1$ and ROS, which may contribute to structural and functional vascular remodeling.

Angiotensin II induces dysfunction and ROS in human brain microvascular endothelial cells, promotes cerebrovascular remodeling, vascular inflammation and results in the impairment of regulation of cerebral blood flow [14]. Comparing with placebo, clinical studies have shown that some RAS-inhibiting agents improve arterial stiffness (as evidenced by a reduction in PWV), endothelial dysfunction or number of EPCs independently of blood pressure reduction. Although data relating the RAS activity to these vascular functions are inconclusive, there are more consistent studies that show that drugs interfering with Ang II reduce arterial stiffness and even decrease arterial-stiffness-associated diseases such as cardiovascular, metabolic and renal disorders [15-18].

Moreover, Ang II directly regulates permeability of BBB ECs via oxidative stress $[19,20]$. Studies have shown that RAS blockade improves cerebrovascular structure, normalizes CBF autoregulation and reduces cerebral ischemia [21-23] while improving vascular compliance and endothelial function in healthy normotensive elderly individuals [24]. Some evidence indicate that RAS blockade therapy may be effective in the prevention of cognitive decline and dementia [25,26], which may be independent of its blood pressure lowering function [27]. Drugs that inhibit the RAS include angiotensin converting enzyme inhibitors (ACEI) and angiotensin receptor blockers (ARB). ACEI blocks ACE and decreases Ang II production while ARB blocks the angiotensin type 1 receptor rather than type 2 . The RAS is involved in the production and clearance of amyloid- $\beta$ $(\mathrm{A} \beta)$ and vascular and inflammatory factors, which may contribute to AD [28, 29]. Thus, ACEI and ARB may be protective against cognitive impairment in hypertensive patients. However, according to several clinical studies, the effects of RAS blockade on cognitive impairment and dementia have been controversial [30]. A meta-analysis that combined randomized clinical trials and observational studies, suggested that the use of RAS blockade was associated with a $35 \%$ reduction in cognitive impairment incidence and $20 \%$ reduction in $\mathrm{AD}$ incidence. Among RAS blockade, ACEI and ARB have $13 \%$ and $31 \%$ association with the decrease in the incidence of $\mathrm{AD}$, respectively, while no significant difference was seen between ACEI and ARB in AD risk. RAS blockade provided a significant reduction in the incidence rate of cognitive impairment with age, with ARB being relatively more effective [31].

\section{$\underline{\text { MFG-E8 }}$}

MFG-E8 is a major component of the human milk fat globule and a multifunctional glycoprotein found in mammary epithelial cells, ECs, VSMCs, dendritic cells, blood cells and fetal hematopoietic stem cells [32-34]. Abundant MFG-E8 expression can be found in advanced human atherosclerotic plaques [35] and certain tumors [36], where it functions in accumulating apoptotic cells, accelerating atherosclerosis and inhibiting neutrophil migration through $\alpha \mathrm{V} \beta 3$-integrin-dependent MAP kinase activation [37]. MFG-E8 is N-linked glycosylated and is overexpressed in the intima and aortic wall media of aged rodents, nonhuman primates and humans.

Double-label immunofluorescence staining show that MFG-E8 co-localizes with a marker of VSMCs, $\alpha$ smooth muscle actin. It co-localizes with Ang II and MCP-1 as well and may take part in developmental homeostatic processes, showing protective effects in various models of organ injury [38, 39]. MFG-E8 is known to support both cell-cell and cell-lipid interactions. It also mediates tissue remodeling of different organs including the vasculature, under pathological conditions $[39,40]$. Treating early passage VSMCs from the young aorta with Ang II can enhance the expression of both MFG-E8 and MCP-1, which are required for increased VSMC invasion. MFG-E8 siRNA can inhibit Ang II induced $\mathrm{MCP}-1$ protein expression, whereas exposure to MFG-E8 increases MCP-1 expression level and invasion capacity of VSMCs; these effects, in turn, are inhibited by a MCP-1 receptor blocker, the poxvirus-derived viral CCchemokine inhibitor protein, vCCI. Conversely, knockdown of MFG-E8 by siRNA also substantially reduces VSMCs invasion capacity. These data suggest that Ang II is upstream of MFG-E8 while MCP-1 is a downstream molecule within the Ang II signaling cascade that regulates VSMC invasion. MFG-E8 is a pivotal relay element within the Ang II/MCP-1/VSMC invasion signaling cascade [40].

MFG-E8 affects VSMC proliferation as well. Exogenously overexpressing MFG-E8 in young VSMCs increases their proliferation rate. Treatment with MFG-E8 triggers a dose-dependent activation of ERK1/2, which are important modulators of mitosis, in both young and aged VSMCs. Exposure to MFG-E8 also enhances levels of PCNA and CDK4, which can be blocked by the ERK1/2 phosphorylation inhibitor, U126, and promotes VSMC proliferation via $\alpha \mathrm{V} \beta 5$ integrins. In contrast, knocking down MFG-E8 by stealth siRNA dramatically reduces PCNA and CDK4 levels and slows down proliferation [41]. Proliferation of VSMC can be 
regulated by PDGF and its receptor-signaling cascade as well [42]. Expression of the PDGF receptor- $\alpha$ and PDGF receptor- $\beta$ is increased in aged VSMCs. MFG-E8 treatment dose- and time-dependently increases expressions of PDGF-A, PDGFR- $\alpha$ and PDGFR- $\beta$, in young and old VSMCs while MFG-E8 siRNA decreases expressions of PDGFR- $\alpha$ and PDGFR- $\beta$ [41]. Collectively, an increase in MFG-E8 signaling may be a mechanism underlying the age-associated increase in aortic VSMC proliferation and invasion.

Endothelial integrity is of great importance to a normal vessel. However, aging enhances endothelial cell (EC) susceptibility to apoptosis. The overexpression of MFG-E8 in ECs triggers apoptosis through increasing the Bax/Bcl-2 ratio and caspase-9 and caspase-3 activation. Knocking down MFG-E8 by siRNA decreases both caspase-3 activity and the phosphorylation of glycogen synthase kinase $3 \beta$, thereby suppressing advanced glycation end product (AGE)-induced apoptosis [43].

\section{$\underline{\text { MMPs }}$}

The extracellular matrix (ECM) maintains vascular structural stability and is essential for the mechanical and biological properties of vessel walls. The ECM is degraded with advancing age, which facilitates VSMC migration.

MEROPS (https://merops.sanger.ac.uk/), an online peptidases database, classifies metalloprotease families into 15 different clans such as MA, MC and 7 unassigned families. MMPs comprise the M10 family of the zinccontaining MA clan of metallopeptidases. They are ubiquitous enzymes, with an active site where a $\mathrm{Zn}$ atom, coordinated by three histidines, can play a catalytic role to degrade the vascular ECM [44]. MMPs involved in vascular ECM remodeling consist of collagenases (MMP1 and MMP-8, expressed by ECs and SMCs), gelatinases (MMP-2, expressed by SMCs and macrophages; MMP-9, expressed in macrophages and vascular cells), elastases (MMP-7, expressed at a low level in the vascular wall, MMP-12, synthesized by macrophages), and stromelysins and membrane-type metalloproteinases (MT-MMPs) [4547]. In addition, MMP-8 can promote the migration and proliferation of VSMCs [47].

Among the family of MMPs, increased MMP-2 and MMP-9 expressions and activities were found to be associated with enhanced Ang II signaling of aged arteries in various species including humans [8, 9, 48, 49]. MMP2 activation is increased during aging, localized to ECs and VSMCs and was detected in the intima, internal elastic lamina and elastin fibers of the inner tunica media [50]. MMP-9 activity is increased in situ during aging in grossly normal aortic segments. Increased MMP-9 levels reduce vascular permeability and induce inflammation, which leads to vessel and perivascular pathophysiological alterations. Additionally, chronic cerebral hypoperfusion associated with vascular aging upregulates MMP-2 expression in microglia and the vascular endothelium of white matter [51].

\section{Calpain-1}

Calpain-1 is a ubiquitous cytosolic $\mathrm{Ca}^{2+}$-activated neutral protease. As discussed in above, increased MMP-2 can be found in aging vessels and MMP-2 activation is implicated in age-associated VSMC migration, elastin degradation and collagen deposition. Calpain-1 regulates MMP-2 activity in VSMCs, facilitating vascular calcification and fibrosis [48] and promoting the invasion of fibroblasts and leukemic cells [52].

Ang II signaling mediates the age-related increase in MMP-2 activity in the vascular wall. This can be blocked using an exogenous or endogenous calpain inhibitor (calpastatin), indicating that calpain activity is required for Ang II-associated activation of MMP-2 [48]. Calpain1 is also linked to cytoskeleton remodeling within VSMCs and VSMC migration as migratory capacity can be stimulated by overexpression of calpain-1 in young VSMCs. Furthermore, calpain-1 has higher mRNA transcript and protein abundance and activity in the aged rat aorta and is regulated by Ang II signaling. Collectively, these findings indicate that increased calpain- 1 activity is a central mechanism for the exaggerated Ang II signaling involved in age-related arterial remodeling.

\section{$\underline{\mathrm{MCP}-1}$}

MCP-1 is a 76-amino acid member of the $\mathrm{C}-\mathrm{C}$ subfamily of chemokines [53]. Through the activation of CCR2, a 7transmembrane $\mathrm{G}$ protein-coupled receptor, MCP-1 can promote the migration of monocytes, lymphocytes, ECs, VSMCs and human fibroblasts as well as induce MMP-1 synthesis [54-56]. MCP-1 also mediates TGF- $\beta$-induced angiogenesis by stimulating VSMC migration. The upregulated expression of MCP-1 and CCR2 could be found in the intima of the aorta of aged rats [57]. MCP-1 expression by vascular cells is regulated by Ang II via the NF-kB-dependent pathway and Ang II levels are upregulated with aging $[58,59]$. Interestingly, an agedependent increase of circulating MCP-1 levels was found in healthy aged people without known diseases. MCP-1 plasma level is increased in older individuals. This means that $\mathrm{MCP}-1$ has the potential to serve as an aging biomarker, although its specific biological significance and functions still need to be further investigated. 


\section{$\underline{\text { TGF- } \beta 1}$}

TGF- $\beta 1$ is a widely expressed cytokine, playing a critical role in the processes of proliferation, wound healing, synthesis of ECM molecules and inflammation. It also has multiple functions in both vascular development and remodeling [60].

TGF- $\beta 1$ is synthesized as a latent precursor molecule (LTGF- $\beta$ ) that contains an amino-terminal hydrophobic signal peptide region, named the latency-associated peptide (LAP). LAP is cleaved from the complex in the Golgi apparatus, but remains non-covalently bonded with TGF- $\beta 1$. LTGF- $\beta$ is secreted as a small latent complex (SLC) or as a large latent complex that is covalently bonded with the LTGF- $\beta$ binding protein (LTBP) [60]. Inflammatory stimuli, MMP-2 and MMP-9 promote the release of TGF- $\beta 1$ from this complex in its mature form, which binds to its receptor and then activates downstream signaling pathways.

The active receptor complex phosphorylates the receptor-activated Smads (R-Smads), Smad2 and Smad3, which propagate the signal. R-Smads form complexes with Smad4 and translocate to the nucleus, where they recruit co-activators or co-repressors into transcriptional complexes and regulate the transcriptional activity of various genes [61]. The signal transduction pathway has its own endogenous regulators as well. An inhibitory Smad, Smad7, blocks TGF- $\beta 1$ signaling by physically interacting with the activated TGFBR1 receptor and prevents the phosphorylation of Smad2/3 [62].

Importantly, upregulated Ang II and MMP2/MMP9 increase the activation of TGF- $\beta 1$ [63, 64]. Signaling molecules downstream of activated TGF- $\beta 1$ (p-Smad-2/$3 /-4)$ are increased while inhibitory Smad (Smad-7) is decreased in the arterial wall with aging [65]. TGF- $\beta 1$ signaling affects ECs function and causes arterial stiffening by increasing collagen types I and III in vessel walls $[66,67]$.

\section{$\underline{\text { ROS and NO bioavailability }}$}

Oxidative stress is widely acknowledged as an important factor associated with aging and disease, which increases in the arterial system of humans and experimental models. It has been linked to the development of age-related pathogenesis, leading to arterial dysfunction. Reactive oxygen species also play a physiological role in the vascular wall, including endothelium-dependent functions, smooth muscle and endothelial cell growth and survival, and regulation of remodeling of the vascular wall [68]. Importantly, oxidative stress can be altered by the imbalance between antioxidant defenses and reactive oxygen species (ROS) that are produced in vessel walls and regulate cell functions and cellular senescence [69].
Imbalance in the regulation of oxidative stress contributes to vascular alterations characterized by mitochondrial dysfunction and increased ROS production, and, eventually, leads to the development of cardiovascular pathological alterations, such as hypertension and stroke.

Ang II can enhance oxidative stress as well as impair endothelial function [70]. Increased Ang II signaling activity can promote the generation of cellular ROS, together with the activation of redox-sensitive signaling cascades [71]. Therefore, ROS may be essential signaling molecules for maintaining vascular homeostasis.

Superoxide molecules are produced by transferring an electron to oxygen; superoxide concentrations can be reduced to the picomolar levels by superoxide dismutase (SOD). However, superoxide molecules react with nitric oxide (NO) at least 10 times faster than SOD can scavenge NO [72]. This reaction may have some biological significance when the concentration of superoxide molecules rises in blood vessels with advancing age [73, 74]. The higher level of superoxide inhibits the generation of NO by vascular cells, resulting in the impairment of endothelium-dependent relaxation. On the other hand, both eNOS activation and NO bioavailability are decreased with age [75, 76]; lower NO levels further increase ROS production. Moreover, peroxynitrite $\left(\mathrm{ONOO}^{-}\right)$, a highly reactive molecule produced by the reaction of NO with superoxide, has been implicated in impaired EC function and vascular aging [74]. Several studies reported the importance of age-related mitochondrial oxidative stress as a characteristic of endothelial dysfunction. It is associated with the overactivation of NADPH oxidase, an enzyme localized in the cytoplasm and membranes. The NADPH oxidases are considered to be enzymatic sources of ROS production in vascular cells, while over-activated NADPH oxidase mediated ROS production is regulated by various factors including hypoperfusion and cytokines and hormones such as Ang II, platelet-derived growth factor, TGF- $\beta$ as well. ROS promote age-related vascular dysfunction not only by compromising EC function, but also inducing the expression of factors involved in vascular structural remodeling such as MMPs [77, 78].

Mitochondrial DNA (mtDNA) is a double-stranded DNA circular genome that encodes 37 genes including tRNA, rRNA and respiratory chain enzymes. MtDNA has a higher mutation rate than nuclear DNA due to the lack of protective histones and the close proximity of the mitochondrial genome to the inner membrane where ROS are continually generated. The amount of mtDNA mutations have been observed to increase as humans age [79] e.g., increased deletions in mtDNA have been reported in the aged human central nervous system and cardiac muscle [80-82]. Mutations of mtDNA may accumulate as a result of unrepaired DNA damage caused 
by ROS or by replication errors that undergo clonal expansion throughtout the adult life [83]. The replication of mtDNA occurs randomly and independently of the cell cycle [84]. Furthermore, a single cell may contain more than one type of mutated mtDNA, namely heteroplasmy. Once it reaches a certain threshold, respiratory chain dysfunction may occur.

Mitochondria oxidative stress increases with age and is a strong trigger of age-related ECs and VSMCs function. Antioxidant enzymes knockout animal models with ablated mitochondrial aldehyde dehydrogenase or mitochondrial superoxide dismutase showed increased mitochondrial ROS formation and oxidative mtDNA lesions. Meanwhile, endothelium-dependent acetylcholine-induced relaxation of aortas was significantly deteriorated. Due to the correlation analysis, mitochondrial ROS formation is directly related to endothelial function while the correlation between mtDNA damage and endothelial dysfunction is relatively less striking but still efficient [85]. Studies showed that $\mathrm{H}_{2} \mathrm{O}_{2}$ is able to induce mtDNA damage in ECs and VSMCs. $\mathrm{H}_{2} \mathrm{O}_{2}$ treatment leads to mtDNA damage within 10 and 15 minutes in ECs and VSMCs, respectively. Apart from $\mathrm{H}_{2} \mathrm{O}_{2}$, either low or high $\mathrm{ONOO}^{-}$concentration causes mtDNA damage in ECs while only high $\mathrm{ONOO}^{-}$ concentration in VSMCs causes mtDNA damage, indicating that ECs are more sensitive to ROS than VSMCs [86]. A mouse model with a homozygous mutation in the exonuclease encoding domain of the $\mathrm{mtDNA}$ polymerase gamma ( $\left.\mathrm{Polg}^{\mathrm{m} / \mathrm{m}}\right)$ that is prone to agedependent accumulation of mtDNA mutations was reported to have increased mitochondrial ROS levels, which resulted in an accelerated form of age-dependent cardiomyopathy. Oxidative stress and respiratory chain dysfunction due to mtDNA point mutations accumulation in protein-coding mitochondrial genes are considered to contribute to the premature aging phenotype of the Polg $^{\mathrm{m} / \mathrm{m}}$ mice. The susceptibility of $\mathrm{mtDNA}$ to oxidative damage may be considered a combination of factors besides the higher superoxide formation rate in the mitochondrial matrix, which is different from nuclear DNA, in that the mtDNA has no protective histones and possesses a low level of DNA repair activity. Therefore, the mitochondrial 8-oxo-deoxyguanosine DNA lesion may be the underlying burden of oxidative stress during the aging process in the heart and brain [87].

Human clinical studies have shown that the mtDNA 4977 deletion levels in the putamen, cortex and cerebellum accumulates with advancing age. The levels of mtDNA damage in the cortex and putamen of the aged brain is much higher than the aged heart [81]. Numerous studies indicated that mtDNA deletion is related to neurodegenerative disorders such as Alzheimer's disease, Parkinson's disease, Huntington's disease and amyotrophic lateral sclerosis [88-91].

Furthermore, mtDNA from atherosclerotic plaques or circulating cells from CVDs patients show increased frequency of mtDNA adducts or the common mitochondrial deletion $\mathrm{mtDNA}^{4977}$, compared with normal vessels or patients without CVDs, respectively [92, 93]. However, the direct correlation between mtDNA damage and neurological diseases via vascular aging remains unclear.

\section{Sex hormones}

\section{Testosterone}

The majority of testosterone is produced by the testis while small amounts are produced by the adrenal glands. Testosterone plays an essential role in the development of the reproductive system, promoting male secondary sexual characteristics.

Testosterone can freely diffuse across the plasma membrane, enter the cytoplasm and bind to the androgen receptor (AR). The hormone-bound $\mathrm{AR}$ acts as a transcription regulatory element that binds to specific DNA response elements in target gene promoters, thereby modulating transcription and protein synthesis [94]. Simultaneously, there are other non-classical and nongenomic mechanisms of testosterone action. Testosterone can activate intracellular signaling molecules such as the mitogen-activated protein kinase (MAPK) family, ERK1/2, protein kinase A and protein kinase $C$ pathways [95]. ARs are widely distributed in cells and organs including ECs and VSMCs [96]. Thus, testosterone levels may influence vascular function in health and disease.

Circulating testosterone in men declines progressively with aging, starting in the early years of adulthood. The decline is paralleled by a number of pathophysiological alterations leading to cardiovascular and cerebrovascular diseases, metabolic syndrome and insulin resistance [97]. Testosterone is involved in vasorelaxation via endothelium-dependent mechanisms, ion channel modulation, and vascular structural remodeling.

Testosterone can modulate endothelial function through NO release [98]. Physiological concentration of testosterone increases NO synthesis by ECs through rapid recruitment of the ERK1/2 and PI3-kinase/Akt signaling pathways [99, 100]. Moreover, testosterone stimulates NO synthesis, which increases cyclic guanosine monophosphate (cGMP) formation in VSMCs to induce vasorelaxation [101]. A low plasma testosterone level is associated with endothelial dysfunction in men independent of other risk factors, suggesting a protective effect of testosterone on the endothelium [102]. In addition, testosterone is metabolized by aromatase to form 
$17 \beta$-estradiol, which stimulates NO release.

Testosterone also modulates ion fluxes in VSMCs by either activating $\mathrm{K}^{+}$channel or inactivating $\mathrm{Ca}^{2+}$ channel. Testosterone within the physiological range is a selective and potent inhibitor of L-type voltage-operated $\mathrm{Ca}^{2+}$ channels, which results in vasodilation [103]. Testosterone also interacts with a large conductance voltage- and $\mathrm{Ca}^{2+}$-activated $\mathrm{K}^{+}\left(\mathrm{BK}_{\mathrm{Ca}}\right.$ or MaxiK) channel, inducing vascular relaxation by increasing intracellular $\mathrm{K}^{+}$efflux [104]. This channel regulates vascular tone and diameter and is a target for various vasoconstrictor and vasodilator agents under physiological conditions. Its expression is reduced in aged coronary arteries, suggesting decreased vasodilating capacity [105]. Longterm testosterone deprivation in rat VSMCs reduces expression of the Kv1.5 voltage-gated $\mathrm{K}^{+}$channel protein whilst restoration of testosterone to physiological concentrations rescues the resulting impairment in Kv1.5 channel function [106]. Intimal-medial thickness and PWV can be reduced by long-term testosterone administration [107, 108], indicating that testosterone replacement can diminish vascular remodeling and arterial stiffness associated with male hypogonadism [109]. Furthermore, low testosterone levels give rise to higher responsiveness to vasoconstrictor agents [104, 110].

Testosterone induces relaxation of isolated blood vessels in vitro. Testosterone levels in men are positively associated with flow-mediated dilatation (FMD) as an independent determinant of endothelial vasomotor function in men [102]. Short-term intracoronary testosterone administration has been reported to induce vasodilation that can increase blood flow in men [111]. A supraphysiological concentration of testosterone was able to trigger direct vasodilator actions via membrane ion channels in isolated blood vessels rather than through the endothelium and AR-dependent pathway [112]. On the other hand, oral supplementation of testosterone in men enhanced FMD without affecting the basal diameter of the brachial artery, suggesting improved endothelial function in men [113]. Progressively lower concentrations of total or free testosterone would be associated with increasing incidence of cerebrovascular events such as incident stroke and transient ischemic attack [114]. However, the relationship between low testosterone level and $\mathrm{AD}$ is not well understood. A meta-analysis of seven prospective cohort studies with a total of 5251 elderly men and 240 cases of Alzheimer's disease, supports the view that low testosterone level is significantly associated with increased risk of $\mathrm{AD}$ in elderly men, which may suggest that testosterone has important roles in regulating cognitive function in elderly men [115]. Nevertheless, although low testosterone level is a risk factor for $\mathrm{AD}$, a long-term testosterone administration study of 36 months in older men with low or low-to-normal testosterone concentrations treatment did not improve cognitive function [116]. This may indicate that testosterone treatment could be used as maintenance therapy in that it lowers the risk of $\mathrm{AD}$, but does not necessarily improve brain function. In addition, Jamadar et al. (117) reviewed 11 clinical studies examining the effects of androgendeprivation therapy (ADT), a mainstay therapy for advanced prostate cancer (PCa), on cognition as measured by standardized tests in cognitive domains. They found that spatial memory and verbal memory may be especially sensitive to ADT, indicating that it is important to consider the benefits of ADT, especially in patients with early stage prostate cancer, which might contribute to vulnerability to negative cognitive effects.

\section{$\underline{\text { Estrogen }}$}

Estrogen is a protective factor for the cardiovascular and cerebrovascular systems [118]. Both types of estrogen receptors (ERs), ER $\alpha$ and $E R \beta$, can be found in the vascular endothelium, SMCs and adventitia. Like testosterone, estrogens bind to nuclear receptors. Activation of ERs regulates gene expression through estrogen-response elements to mediate transcription. Estrogen can also bind to plasma membrane sites thus inhibiting $\mathrm{Ca}^{2+} \mathrm{L}$-type voltage-gated channels in VSMCs and activating several signaling pathways including the PI3K pathway in ECs $[119,120]$.

Estrogen is known to mediate vascular function by increasing NO bioavailability and suppressing ROS levels. Estrogen modulates vasoconstrictive factors or positively upregulates vasodilating factors such as prostacyclin $\left(\mathrm{PGI}_{2}\right)$. Estrogen also inhibits the expression or function of cyclooxygenase-derived vasoconstrictors including prostaglandin $\mathrm{H} 2$ and thromboxane $\mathrm{A} 2$, which are mediators of vascular tone in females [121]. Furthermore, ACE activity can be decreased by estrogen therapy, which reduces Ang II production, seen in both animal models and postmenopausal females. Moreover, estrogen attenuates AT1 receptor expression and AT1-mediated responses in the aorta, heart, and kidneys [122].

In middle-aged women, subclinical vascular dysfunction may be aggravated by estrogen deficiency due to menopause or ovariectomy, which may be improved by estrogen replacement. However, some evidence suggest that estrogen can delay the progression of atherosclerotic lesions, measured by carotid artery intima-media thickness, in early postmenopausal women [123]. Beneficial effects of estrogen replacement therapy on mood and cognition in early but not late postmenopausal women have also been reported [124, 125]. Further research into sex hormone deficiency related to vascular dysfunction is still necessary to define 
optimal diagnostic and therapeutic strategies.

The menstrual cycle may be a great estrogen fluctuation cycle for studying the function of estrogen on vascular function. A comprehensive study reported that FMD, acetylcholine administration to skin microvessels via iontophoresis and arterial compliance, were all consistently reduced during the early luteal phase, while pulse wave velocity did not $[126,127]$, suggesting that vascular endothelial function possibly fluctuates with hormonal changes throughout the menstrual cycle although there was little alteration found in arterial stiffness. However, longer periods of estrogen deficiency may trigger changes in arterial stiffness. Several studies have reported the augmenting age-related increase in arterial stiffness in postmenopausal women [128-131]. Moreover, the evidence is inconclusive on the relationship between menopause and cognition. Some suggest that menopause at younger ages was associated with reduced cognitive performance in later years [132, 133], while others reported that no clinically significant changes were found with respect to cognitive function $[134,135]$ or that only short-lasting cognitive decline was observed in limited domains with menopause [136, 137].

\section{Diseases linked to vascular aging}

Blood pressure changes with advancing age. There is a linear rise in systolic blood pressure induced by arterial stiffness and a concurrent increase in diastolic blood pressure due to endothelial dysfunction-induced high peripheral vascular resistance until about the age of 50 [138]. Thereafter, high systolic blood pressure accelerates arterial stiffness, perpetuating a vicious cycle. In older individuals, increased arterial stiffness decreases diastolic blood pressure while systolic blood pressure keeps rising, which forms an age-related systolic-diastolic blood pressure divergence, resulting in a widen pulse pressure. Even in older normotensives, they have higher arterial stiffness, systolic blood pressure and pulse pressure $v s$. the young [139]. Increasing pulse pressure or hypertension increases cardiac afterload, then leads to left ventricular hypertrophy. In the brain, increased pulse pressure penetrates further into cerebral microcirculation, which may potentially expose capillaries to damaging levels of elevated pressure pulsatility. Thus, cerebral microvascular remodeling and dysfunction increase vascular resistance in response to elevated pulse pressure and limit the penetration of excessive pulsatility directly into the capillaries [140]. However, cerebral microvascular remodeling and dysfunction increases minimal resistance and reduces vasodilatory reserve. Accompanying age-related microvessel loss, these lead to an increased susceptibility to hypoperfusion and reduce the efficiency of oxygen and energy delivery, which can promote cerebral microvascular disease $[141,142]$ and cognitive impairment [143, 144].

Thus, vascular aging may be linked with neurological diseases in two parallel pathways: (1) reduction in brain microcirculation, arterial stiffening, endothelial dysfunction causing hypoperfusion and (2) blood-brain barrier breakdown associated with brain accumulation of serum proteins and several vasculotoxic and/or neurotoxic macromolecules ultimately leading to secondary neuronal degenerative changes.

\section{Alzheimer's disease and vascular cognitive impairment}

Dementia is a disorder of cognitive impairment that interferes with everyday life. Alzheimer's disease (AD) is the most common cause of dementia and is rare before 60 years of age [145]; vascular cognitive impairment (VCI) is a group of cognitive disorders with a presumed vascular cause and has generally superseded the term vascular dementia. In addition to AD and VCI's adverse effects on affected individuals and their families, dementia greatly increases demands on the medical care system. VCI is a larger concept that includes VCI-no dementia, vascular dementia (VD) and cognitive impairment of mixed origin (Alzheimer's disease and vascular dementia) [146]. In this section, we focus on vascular-related cognitive impairment by reviewing recent studies.

Several reports have shown that vascular aging is associated with both $\mathrm{AD}$ and VD. Hanon et al. [147] observed that PWV was elevated in AD $(13.3 \pm 2.9 \mathrm{~m} / \mathrm{s})$ and VD $(15.2 \pm 3.9 \mathrm{~m} / \mathrm{s})$ patients compared with controls $(11.5 \pm 2.0 \mathrm{~m} / \mathrm{s})$, suggesting that arterial stiffness may be involved in the development of these disorders. Calik, et al. [148] pointed out that arterial diastolic dysfunction and increased arterial stiffness are detected in AD patients. Other studies have demonstrated that vascular stiffness is an independent risk factor for and has potential to be a strong predictor of cognitive loss $[149,150]$. Interestingly, PWV is significantly higher in VD than in AD [151], which has a more complex etiology in which the contribution of vascular disease is less clear. Endothelial dysfunction may associate with cognitive impairment in the elderly population as well. It was reported that mildly cognitive impaired patients with prevalent amnestic multiple domains exhibited much worse brachial FMD [152].

Arterial stiffness is largely associated with $A \beta$ deposition, either by baseline comparison or accumulating in the brain over the years in non-demented elderly adults; this association differs with different arterial bed measurements [153, 154]. Peripheral rather than central vascular stiffness is relatively stronger in the correlation with the amount of $A \beta$ being deposited whilst systemic arterial stiffness (a composite parameter of 
central and peripheral arteries) or central arterial stiffness is strongly correlated with the progression of $A \beta$ accumulation. Furthermore, as a result of arterial stiffness and endothelial dysfunction, pulse pressure increases and becomes a risk factor for $\mathrm{AD}$ and dementia in older adults [155]. High pulse pressure promotes vascular remodeling, which further impairs vascular function. Clinical data showed that increased pulse pressure is related to reduced cerebrospinal fluid $A \beta$, indicating that elevated pulse pressure may affect the clearance of $A \beta$ [156]. This was confirmed by another group that pulse pressure elevation was significantly associated with reduced cerebrospinal fluid $A \beta$ in the aged group [157].

An alternative mechanism may involve reduced cerebral blood flow (CBF). Decreased CBF was observed by arterial spin-labeling MRI in the frontal and parietal cortices of human subjects with either AD or VD [158]. Total (tCBF) and mean CBF decrease with age whereas pulsatile CBF velocity increases [159], perhaps due to the age-related increase in stiffness of elastic arteries and decreased compliance of muscular arteries and arterioles. Interestingly, females have relatively higher tCBF and lower cerebrovascular resistance than males [160]. In vivo studies demonstrated that subsequent hypoperfusion accelerates deposition of $A \beta$ via increased generation and impaired clearance and could cause cognitive impairment $[142,161]$. Greater $A \beta$ concentration decreases the production of NO, thus causing a significant decrease in endothelial-dependent vasodilation along with the induction oendothelial cell apoptosis [162-164].

\section{Stroke}

Stroke is the leading cause of death worldwide that accounts for about 1 in 10 deaths or 5.7 million deaths a year. Stroke incidence is doubled in low- and middleincome regions compared with those living in highincome regions [165]. It can be fatal or dramatically decrease the quality of life in survivors and often necessitates extremely costly medical care. Stroke incidence increases with advancing age, so research on the relationship between vascular aging and stroke could have significant clinical benefits.

Arterial stiffness is an independent predictor for fatal stroke as demonstrated in a long-term clinical study of 1715 patients with essential hypertension whose carotidfemoral PWV was measured at entry. Importantly, the predictive value of PWV remained significant even after full adjustment for classical cardiovascular risk factors such as age, gender, cholesterol level, diabetes and smoking [166]. Another study comprising 2835 participants in the third examination phase of the Rotterdam Study, demonstrated that arterial stiffness is an independent predictor of stroke among otherwise healthy subjects. During follow-up, 63 subjects developed a stroke (mean follow-up period, 3.2 years). Among this group, the risk of stroke increased with increasing aortic PWV index. Although other comorbidities of aging such as obesity and diabetes limit the predictive value of the conventional cardiovascular risk factors, PWV may be an independent predictor of coronary heart disease and stroke [167]. Willum-Hansen, et al. [168] also documented the prognostic value of PWV in a 1678-person populationbased study. The meta-analysis consisted 10 studies that revealed that carotid stiffness is strongly associated with a higher stroke incidence, independent of aortic stiffness, supporting the idea that carotid stiffening is an important factor in the pathogenesis of stroke [169]. Indeed, the increased pulse wave is able to go through the carotid artery quickly and penetrate distally into the cerebral microcirculation, which may promote hypertrophic remodeling and induce chronic ischemia by hypoperfusion.

Arterial stiffness also serves as a predictor of stroke outcome. Low carotid-femoral PWV is significantly associated with excellent stroke outcome, even after adjustment for age, baseline NIHSS score on admission and stroke history [170]. In stroke patients, aortic PWV helps predict asymptomatic coronary artery disease beyond the predictive ability of classical risk factors. In fact, coronary artery disease is a significant cause of morbidity and mortality in patients who have had a stroke [171]. Further, arterial stiffness is independently related to cerebral microbleeds in patients with stroke [172].

Endothelial dysfunction is another potentially adverse alteration with advancing age in stroke development. Endothelial dysfunction reduces the tone of aging arteries and increases their sensitivity to vasoconstrictors or stimulus, which may result in a higher risk of acute or chronic ischemia. It has been reported that acute ischemic stroke patients have severe endothelial dysfunction [173]. More specifically, the relationship between endothelial dysfunction and stroke subtypes has been studied, which revealed that only lacunar stroke is closely related with endothelial dysfunction [174]. Endothelial dysfunction may be involved in the pathogenesis of lacunar stroke especially in those subjects with concomitant silent lacunar infarcts and ischemic white matter hyperintensities (WMH) [175]. Endothelial function measured by brachial FMD is impaired in stroke patients compared with healthy controls, which has also been observed in other studies [176, 177]. Selecting homocysteine, von Willebrand factor (vWF), E-selectin, P-selectin, intercellular adhesion molecule-1 (ICAM), and vascular cellular adhesion molecule-1 (VCAM) as blood markers of endothelial dysfunction, Wiseman et al. [178] found that these markers were significantly increased in lacunar stroke $v s$. the non-stroke group. On 
the cerebrovascular level, by assessing cerebral vasoreactivity and extracerebral vascular functions in symptomatic lacunar stroke patients and non-stroke controls, symptomatic lacunar stroke patients had more severe endothelial dysfunction in the cerebral arteries while relatively smaller difference of extracerebral arterial abnormalities were found. Thus, endothelial dysfunction of brain vessels can be an important determinant of lacunar stroke [179]. Overall, vascular aging may have important roles in stroke pathogenesis and could be a potential marker of stroke risk and outcome.

Table 1. Devices and methods used for evaluating arterial stiffness.

\begin{tabular}{llll}
\hline Device & Manufacturer & Method & Region or arterial site \\
\hline $\begin{array}{c}\text { Regional arterial stiffness } \\
\text { Sphygmocor }\end{array}$ & AtCor Medical, Au & Pressure & cfPWV \\
Diasys & Novacor, Fr & Korotkov sounds \& ECG & baPWV \\
Omron VP-1000 & Omron Healthcare, Jp & Pressure & cfPWV, baPWV, faPWV \\
Vasera system & Fukuda Denshi, Jp & Pressure \& ECG & Cardio-ankle vascular index \\
Mobil-O-Graph & I.E.M. Ge & Pressure & cfPWV \\
PulsePen & Diatechne, It & Pressure \& ECG & cfPWV \\
PulseTrace & Micromedical, UK & Doppler \& ECG & cfPWV, baPWV \\
Vicorder & SMT medical GmbH \& Co, Ge & Pressure & cfPWV, baPWV \\
pOpmètre & Axelife SAS, Fr & Photodiodes sensors & Finger-toe PWV \\
Local arterial stiffness & & & \\
Artlab system & Esaote, It & Ultrasound & CCA, CFA, BA \\
E-Tracking & Aloka, Jp & Ultrasound & CCA, CFA, BA \\
MRI & - & Cine-MRI & Aorta \\
\hline
\end{tabular}

ECG, electrocardiography; CCA, common carotid artery; CFA, common femoral artery; BA, branchial artery

\section{Other neurological diseases}

Cerebral small vessel disease (SVD) is common in aged people and can be potentiated by hypertension and diabetes mellitus [180]. SVD can be visualized by MRI as $\mathrm{WMH}$, lacunar infarcts, and cerebral microbleeds [181]; it also contributes to the development of cognitive decline and dementia $[182,183]$. Several studies have reported an association between arterial stiffness (measured based on brachial-ankle or carotid-femoral pulse wave velocity) and SVD [184-187]. Age is associated with WMH, although the relationship between age and lacunar infarction, in particular, differs among studies. Some studies report no statistically significant link [188, 189], but this may be explained by the relatively young population (mean age 46.9-58.2 years) and the low prevalence of lacunar infracts $(4.3 \%)$. When older populations were examined, arterial stiffness was shown to be associated with lacunar infarcts [185, 190-192]. Brain atrophy is also related to vascular aging [193, 194]. Increased aorta or carotid stiffness is associated with larger WMH and increased carotid stiffness is associated with decreased total brain parenchyma, grey matter and especially, white matter volumes. These associations were even stronger in uncontrolled hypertension and aged patients [195].
Taken together, vascular aging may affect the process and outcome of neurological diseases including dementia, cognitive impairment and stoke. Therefore, it needs to be carefully considered as an important detrimental factor in these diseases, especially in certain populations such as patients with hypertension.

Considering the importance of the cerebral blood supply for brain function, SVD, thus, has a great impact on cognitive function. The vascular alterations-induced vascular dysfunction that finally leads to cognitive impairment are diverse, which includes hemodynamic changes or alterations on cerebral blood vessels. General hypoperfusion can produce transient or permanent cognitive impairment [196], which is a result of structural and functional age-related changes. The most acknowledged vascular lesions promoting vascular cognitive impairment is SVD, especially in white matter [197]. These lesions often coexist in one single patient and contribute to the cognitive impairment. Lacunar infarcts and leukoaraiosis that are common in VCI are also associated with arterial stiffness. Patients with leukoaraiosis have higher PWV that transmits increased pulse pressure into the brain through the middle cerebral artery [198]. Tortuous arterioles, increased intima-media thickness, reduced capillaries number and length may be the underlying vascular alterations. Microbleeds is a 
predictor of cognitive dysfunction and arterial stiffness may be important in the development of microbleeds, especially in stroke patients $[172,199]$. Furthermore, it is well known that $A \beta$ deposition or cerebral amyloid angiopathy is associated with vascular cognitive impairment, although it seems to be a "marker" of AD, with it being present in over $90 \%$ of patients [200]; it can be promoted by arterial aging-induced arterial stiffness and endothelial dysfunction. AD-related cerebrovascular lesions and VCIs are similar. Data containing different average prevalence of leukoaraiosis and lacunar infarcts, microbleeds, microinfarcts, $\mathrm{A} \beta$ deposition as well as hypoperfusion in AD and VCI or VD could reveal the pattern of vascular alterations in these diseases. A previous review reported that the most remarkable vascular-related difference between $\mathrm{AD}$ and VCI is cerebral amyloid angiopathy and microinfarcts/lacunes [200]. Cerebral amyloid angiopathy can be found in almost $98 \%$ of AD patients $v$ s. $30 \%$ of VCI patients and $23-45 \%$ of aged controls. Microinfarcts/lacunes were seen in $70 \%$ of VCI patients $v s .10-15 \%$ of AD patients and just over $10 \%$ of aged controls.

Table 2. Approaches for assessing endothelial function.

\begin{tabular}{lll}
\hline Method & Vascular site & $\begin{array}{l}\text { Invasive or } \\
\text { Non-invasive }\end{array}$ \\
\hline $\begin{array}{l}\text { Coronary epicardial } \\
\text { vasoreactivity }\end{array}$ & Coronary & Invasive \\
\hline FMD & $\begin{array}{l}\text { Peripheral conduit } \\
\text { artery }\end{array}$ & Non-invasive \\
\hline EndoPAT & $\begin{array}{l}\text { Small arteries and } \\
\text { finger } \\
\text { microvasculature }\end{array}$ & Non-invasive \\
\hline $\begin{array}{l}\text { Intracoronary } \\
\text { doppler wire }\end{array}$ & $\begin{array}{l}\text { Coronary } \\
\text { microcirculation }\end{array}$ & Invasive \\
\hline $\begin{array}{l}\text { Venous occlusion } \\
\text { plethysmography }\end{array}$ & Forearm vein & Invasive \\
\hline
\end{tabular}

\section{Clinical investigation of vascular aging}

\section{Measurements}

There are many methods that can be used for assessing vascular aging. As vascular aging is a ubiquitous phenomenon with both clinical and subclinical manifestations, large-scale application of invasive techniques may be inappropriate and can lead to overtreatment.

Arterial stiffness can be assessed at different levels, either regional or local. For regional arterial stiffness assessment, PWV seems to be a widely used and reproducible approach. Central arterial stiffness can only be estimated by PWV between the common carotid artery
(CCA) and the common femoral artery (cfPWV). cfPWV is often thought to be the gold standard for measuring arterial stiffness as it evaluates the arteries from the aortic through the aortoiliac pathway including big branches, which are essential in the hemodynamic load for the end organ [201]. The femoral-ankle PWV (faPWV) is considered a peripheral arterial stiffness index. Furthermore, brachial-ankle (baPWV) assesses the mechanical property of a large territory, integrating both the large-sized central elastic and medium-sized peripheral muscular arteries thus correlating better with left ventricular mass and diastolic function and other indices of arterial function than cf-PWV; it also can possibly be considered a relative systemic index of arterial stiffness [202]. For local arterial stiffness, superficial arteries can be directly measured by ultrasound. The carotid may be a region with great interest to clinicians not only because it is a superficial artery, but it also is a high incidence region of atherosclerosis. All types of classic bi-dimensional vascular ultrasound devices can probably be used to examine parameters including local arterial distensibility, diameter and thickness. However, because of the limitation of ultrasound technology itself, the readings from devices always differ from clinician to clinician, even with the same device. Thus, there is increasing interest in measuring arterial stiffness through MRI. Interestingly, faster and more robust MRI sequences have enabled MRI-based PWV measurements. Nonetheless, the lack of compatible computing software limited the use of MRI-based PWV [203]. Because of its ease and wide clinical utility coupled with a much lower cost, the ultrasound technology is still the most prevalent method for local arterial stiffness assessment (Table 1).

Endothelial dysfunction is a pathological condition during aging. Similar to measurements for arterial stiffness, endothelial function assessment would require stimulating the human body by pacing or exercise, or stimulating the arteries locally by acetylcholine or reactive hyperemia, then investigate if the blood flow or dilation increases as healthy arteries are expected to. Despite its high cost and invasive process, coronary epicardial vasoreactivity is the gold standard for epicardial macrovascular endothelial dysfunction (Table 2). However, for an asymptomatic individual, noninvasive and cheaper measurements would be appropriate for screening. As a noninvasive approach, FMD has been the most commonly used measurement of endothelial function of the brachial or other peripheral conduit artery. It measures the artery's response to endothelial NO during reactive hyperemia after a 5-minute occlusion of the brachial artery using a blood pressure cuff to estimates endothelial function. Measuring endothelial function with peripheral arterial tonometry (EndoPAT) is another noninvasive approach that evaluates changes in finger arterial 
pulse wave amplitude under the stimulation of reactive internal control [204]. hyperemia. The contralateral arm could serve as an

Table 3. Potential intervention measures for vascular aging.

\begin{tabular}{llll}
\hline \multicolumn{1}{c}{ Intervention Measure } & \multicolumn{1}{c}{ Influence of intervention } & Underlying Mechanism & Reference \\
\hline Exercise & $\begin{array}{l}\text { Decreases vessel tortuosity, } \\
\text { cardiovascular morbidity and } \\
\text { mortality }\end{array}$ & eNOS $\uparrow$ & ROS $\downarrow$ \\
& $\begin{array}{l}\text { Increases CBF, capillary } \\
\text { vascularity }\end{array}$ & \\
& Maintain endothelial function & & \\
& Decreases serum cholesterol, & eNOS $\uparrow$ & \\
arterial stiffness and attenuate & ROS $\downarrow$ \\
valoric restriction & Protects endothelial function & Circulating C-reactive & \\
& protein (CRP) $\downarrow$ & [208, 209] \\
& Decreases PWV & TNF $\downarrow$ & \\
\hline Statins & Protects endothelial function & Serum CRP $\downarrow$ & [210-212] \\
& Anti-vascular inflammation & Activity of NF-kB $\downarrow$ & \\
& & ROS $\downarrow$ & {$[15,213,214]$} \\
\hline RAS Drugs & Decreases PWV & Block Ang II signaling & \\
\hline
\end{tabular}

\section{Potential intervention measures}

As life expectancy is expected to increase with the use of modern medical technologies, biomedical research is likely to focus increasingly on cerebrovascular and cardiovascular diseases. Consequently, numerous research groups consider vascular aging an important area of research (Table 3). However, even in the case of less invasive strategies such as exercise and diet, purported benefits of new interventions must be weighed against potential adverse effects.

\section{Summary}

The molecular targets through which aging perturbs vascular homeostasis are manifold and appear to include increased expression or activation of TNF- $\alpha$, IL-1 $\beta$, IL-6 family members and CRP, which promote inflammation and endothelial dysfunction. Currently, there are many non-invasive ways to examine vascular aging through arterial stiffness and endothelial function assessments. New interventions such as the use of statins and RAS drugs to treat vascular aging have been suggested, but clinicians and patients should consider potential adverse effects.

What may seem like an insurmountable task with regard to the treatment for vascular dysfunction may in fact hold much promise and excitement. It will take a concerted effort from researchers and clinicians to work together to advance the field of vascular aging and find interventions to promote cardiovascular and cerebrovascular health in the elderly.

\section{Acknowledgements}

This work was supported by the China Scholarship Council (No. 201406320118) (to XX), American Heart Association Predoctoral Fellowship (15PRE25700416) (to BW), Sigma Xi Grants-in-Aid of Research (G201503151162287) (to BW), National Natural Science Foundation of China (81301996) (to TC), Ph.D. Programs Foundation of Ministry of Education of China (20130101120017) (to TC). National Institutes of Health grant NS084148-01A1 (to KJ), the National Science Foundation of Beijing (No. 7161014) (to KJ).

\section{References}

[1] Ungvari Z, Kaley G, de Cabo R, Sonntag WE, Csiszar A (2010). Mechanisms of vascular aging: new perspectives. J Gerontol A Biol Sci Med Sci, 65: 10281041

[2] Lozano R, Naghavi M, Foreman K, Lim S, Shibuya K, Aboyans V, et al. (2012). Global and regional mortality from 235 causes of death for 20 age groups in 1990 and 2010: a systematic analysis for the Global Burden of Disease Study 2010. Lancet, 380: 2095- 


\section{8}

[3] Nichols M, Townsend N, Scarborough P, Rayner M (2014). Cardiovascular disease in Europe 2014: epidemiological update. Eur Heart J, 35: 2950-2959

[4] Wang M, Jiang L, Monticone RE, Lakatta EG (2014). Proinflammation: the key to arterial aging. Trends Endocrinol Metab, 25: 72-79

[5] Stegbauer J, Coffman TM (2011). New insights into angiotensin receptor actions: from blood pressure to aging. Curr Opin Nephrol Hypertens, 20: 84-88

[6] Basso N, Cini R, Pietrelli A, Ferder L, Terragno NA, Inserra F (2007). Protective effect of long-term angiotensin II inhibition. Am J Physiol Heart Circ Physiol, 293: H1351-H1358

[7] Wang M, Takagi G, Asai K, Resuello RG, Natividad FF, Vatner DE, et al. (2003). Aging increases aortic MMP-2 activity and angiotensin II in nonhuman primates. Hypertension, 41: 1308-1316

[8] Wang M, Zhang J, Jiang LQ, Spinetti G, Pintus G, Monticone R, et al. (2007). Proinflammatory profile within the grossly normal aged human aortic wall. Hypertension, 50: 219-227

[9] Wang M, Zhang J, Spinetti G, Jiang LQ, Monticone R, Zhao D, et al. (2005). Angiotensin II activates matrix metalloproteinase type II and mimics age-associated carotid arterial remodeling in young rats. Am J Pathol, 167: 1429-1442

[10] Xie X, Chen J, Wang X, Zhang F, Liu Y (2006). Ageand gender-related difference of ACE2 expression in rat lung. Life Sci, 78: 2166-2171

[11] Rajagopalan S, Brook R, Mehta RH, Supiano M, Pitt B (2002). Effect of losartan in aging-related endothelial impairment. Am J Cardiol, 89: 562-566

[12] Modrick ML, Didion SP, Sigmund CD, Faraci FM (2009). Role of oxidative stress and AT1 receptors in cerebral vascular dysfunction with aging. Am J Physiol Heart Circ Physiol, 296: H1914-H1919

[13] Wolf G, Wenzel U, Burns KD, Harris RC, Stahl RA, Thaiss F (2002). Angiotensin II activates nuclear transcription factor-kappaB through AT1 and AT2 receptors. Kidney Int, 61: 1986-1995

[14] Tota S, Goel R, Pachauri SD, Rajasekar N, Najmi AK, Hanif K, et al. (2013). Effect of angiotensin II on spatial memory, cerebral blood flow, cholinergic neurotransmission, and brain derived neurotrophic factor in rats. Psychopharmacology (Berl), 226: $357-$ 369

[15] Topouchian J, El FR, Pannier B, Wang S, Zhao F, Smetana K, et al. (2007). Arterial stiffness and pharmacological interventions--the TRanscend arterial stiffNess Substudy (TRANS study). Vasc Health Risk Manag, 3: 381-387

[16] Werner C, Baumhakel M, Teo KK, Schmieder R, Mann J, Unger T, et al. (2008). RAS blockade with ARB and ACE inhibitors: current perspective on rationale and patient selection. Clin Res Cardiol, 97: 418-431

[17] Perret-Guillaume C, Joly L, Jankowski P, Benetos A (2009). Benefits of the RAS blockade: clinical evidence before the ONTARGET study. J Hypertens
[18] Sohn SI, Kim CJ (2014). Modulation of reninangiotensin system and arterial stiffness: evidence from clinical trials. Curr Hypertens Rev, 10: 37-40

[19] Fleegal-DeMotta MA, Doghu S, Banks WA (2009). Angiotensin II modulates $\mathrm{BBB}$ permeability via activation of the $\mathrm{AT}(1)$ receptor in brain endothelial cells. J Cereb Blood Flow Metab, 29: 640-647

[20] Zhang M, Mao Y, Ramirez SH, Tuma RF, Chabrashvili T (2010). Angiotensin II induced cerebral microvascular inflammation and increased blood-brain barrier permeability via oxidative stress. Neuroscience, 171: 852-858

[21] Nishimura Y, Ito T, Saavedra JM (2000). Angiotensin II AT(1) blockade normalizes cerebrovascular autoregulation and reduces cerebral ischemia in spontaneously hypertensive rats. Stroke, 31: 24782486

[22] Dupuis F, Atkinson J, Liminana P, Chillon JM (2005). Captopril improves cerebrovascular structure and function in old hypertensive rats. Br J Pharmacol, 144: 349-356

Estato V, Obadia N, Carvalho-Tavares J, Freitas FS, Reis P, Castro-Faria NH, et al. (2013). Blockade of the renin-angiotensin system improves cerebral microcirculatory perfusion in diabetic hypertensive rats. Microvasc Res, 87: 41-49

[24] Rajagopalan S, Kariisa M, Dellegrottaglie S, Bard RL, Kehrer C, Matlow S, et al. (2006). Angiotensin receptor blockade improves vascular compliance in healthy normotensive elderly individuals: results from a randomized double-blind placebo-controlled trial. J Clin Hypertens (Greenwich), 8: 783-790

[25] Fournier A, Oprisiu-Fournier R, Serot JM, Godefroy O, Achard JM, Faure S, et al. (2009). Prevention of dementia by antihypertensive drugs: how AT1receptor-blockers and dihydropyridines better prevent dementia in hypertensive patients than thiazides and ACE-inhibitors. Expert Rev Neurother, 9: 1413-1431

[26] Shah K, Qureshi SU, Johnson M, Parikh N, Schulz PE, Kunik ME (2009). Does use of antihypertensive drugs affect the incidence or progression of dementia? A systematic review. Am J Geriatr Pharmacother, 7: 250-261

[27] McGuinness B, Todd S, Passmore P, Bullock R (2009). Blood pressure lowering in patients without prior cerebrovascular disease for prevention of cognitive impairment and dementia. Cochrane Database Syst Rev, D4034

[28] Marchesi VT (2011). Alzheimer's dementia begins as a disease of small blood vessels, damaged by oxidative-induced inflammation and dysregulated amyloid metabolism: implications for early detection and therapy. Faseb J, 25: 5-13

[29] Hajjar I, Rodgers K (2013). Do angiotensin receptor blockers prevent Alzheimer's disease? Curr Opin Cardiol, 28: 417-425

[30] Chang-Quan H, Hui W, Chao-Min W, Zheng-Rong W, Jun-Wen G, Yong-Hong L, et al. (2011). The association of antihypertensive medication use with 
risk of cognitive decline and dementia: a meta-analysis of longitudinal studies. Int J Clin Pract, 65: 1295-1305

[31] Zhuang S, Wang HF, Wang X, Li J, Xing CM (2016). The association of renin-angiotensin system blockade use with the risks of cognitive impairment of aging and Alzheimer's disease: A meta-analysis. J Clin Neurosci, [32] Brissette MJ, Lepage S, Lamonde AS, Sirois I, Groleau J, Laurin LP, et al. (2012). MFG-E8 released by apoptotic endothelial cells triggers antiinflammatory macrophage reprogramming. Plos One, 7: e36368

[33] Lee J, Choi BI, Park SY, An SY, Han J, Kim JH (2015). Fetal hematopoietic stem cells express MFG-E8 during mouse embryogenesis. Exp Mol Med, 47: e174

[34] Veron P, Segura E, Sugano G, Amigorena S, Thery C (2005). Accumulation of MFG-E8/lactadherin on exosomes from immature dendritic cells. Blood Cells Mol Dis, 35: 81-88

[35] Ait-Oufella H, Kinugawa K, Zoll J, Simon T, Boddaert J, Heeneman S, et al. (2007). Lactadherin deficiency leads to apoptotic cell accumulation and accelerated atherosclerosis in mice. Circulation, 115: 2168-2177

[36] Neutzner M, Lopez T, Feng X, Bergmann-Leitner ES, Leitner WW, Udey MC (2007). MFG-E8/lactadherin promotes tumor growth in an angiogenesis-dependent transgenic mouse model of multistage carcinogenesis. Cancer Res, 67: 6777-6785

[37] Aziz M, Yang WL, Corbo LM, Chaung WW, Matsuo S, Wang P (2015). MFG-E8 inhibits neutrophil migration through alphavbeta(3)-integrin-dependent MAP kinase activation. Int J Mol Med, 36: 18-28

[38] Cheyuo C, Jacob A, Wu R, Zhou M, Qi L, Dong W, et al. (2012). Recombinant human MFG-E8 attenuates cerebral ischemic injury: its role in anti-inflammation and anti-apoptosis. Neuropharmacology, 62: 890-900

[39] Raymond A, Ensslin MA, Shur BD (2009). SED1/MFG-E8: a bi-motif protein that orchestrates diverse cellular interactions. J Cell Biochem, 106: 957-966

[40] Fu Z, Wang M, Gucek M, Zhang J, Wu J, Jiang L, et al. (2009). Milk fat globule protein epidermal growth factor-8: a pivotal relay element within the angiotensin II and monocyte chemoattractant protein-1 signaling cascade mediating vascular smooth muscle cells invasion. Circ Res, 104: 1337-1346

[41] Wang M, Fu Z, Wu J, Zhang J, Jiang L, Khazan B, et al. (2012). MFG-E8 activates proliferation of vascular smooth muscle cells via integrin signaling. Aging Cell, 11: 500-508

[42] Marrero MB, Schieffer B, Li B, Sun J, Harp JB, Ling BN (1997). Role of Janus kinase/signal transducer and activator of transcription and mitogen-activated protein kinase cascades in angiotensin II- and plateletderived growth factor-induced vascular smooth muscle cell proliferation. J Biol Chem, 272: 2468424690

[43] Li BY, Li XL, Cai Q, Gao HQ, Cheng M, Zhang JH, et al. (2011). Induction of lactadherin mediates the apoptosis of endothelial cells in response to advanced glycation end products and protective effects of grape seed procyanidin B2 and resveratrol. Apoptosis, 16: 732-745

[44] Sbardella D, Fasciglione GF, Gioia M, Ciaccio C, Tundo GR, Marini S, et al. (2012). Human matrix metalloproteinases: an ubiquitarian class of enzymes involved in several pathological processes. Mol Aspects Med, 33: 119-208

[45] Galis ZS, Khatri JJ (2002). Matrix metalloproteinases in vascular remodeling and atherogenesis: the good, the bad, and the ugly. Circ Res, 90: 251-262

[46] Jacob MP (2003). Extracellular matrix remodeling and matrix metalloproteinases in the vascular wall during aging and in pathological conditions. Biomed Pharmacother, 57: 195-202

[47] Xiao Q, Zhang F, Grassia G, Hu Y, Zhang Z, Xing Q, et al. (2014). Matrix metalloproteinase-8 promotes vascular smooth muscle cell proliferation and neointima formation. Arterioscler Thromb Vasc Biol, 34: 90-98

[48] Jiang L, Zhang J, Monticone RE, Telljohann R, Wu J, Wang M, et al. (2012). Calpain-1 regulation of matrix metalloproteinase 2 activity in vascular smooth muscle cells facilitates age-associated aortic wall calcification and fibrosis. Hypertension, 60: 11921199

[49] Li Z, Froehlich J, Galis ZS, Lakatta EG (1999). Increased expression of matrix metalloproteinase- 2 in the thickened intima of aged rats. Hypertension, 33: 116-123

[50] McNulty M, Spiers P, McGovern E, Feely J (2005). Aging is associated with increased matrix metalloproteinase-2 activity in the human aorta. Am J Hypertens, 18: 504-509

[51] Ihara M, Tomimoto H, Kinoshita M, Oh J, Noda M, Wakita H, et al. (2001). Chronic cerebral hypoperfusion induces MMP-2 but not MMP-9 expression in the microglia and vascular endothelium of white matter. J Cereb Blood Flow Metab, 21: 828834

[52] Popp O, Heidinger M, Ruiz-Heinrich L, Ries C, Jochum M, Gil-Parrado S (2003). The calpastatinderived calpain inhibitor $\mathrm{CP} 1 \mathrm{~B}$ reduces mRNA expression of matrix metalloproteinase- 2 and -9 and invasion by leukemic THP-1 cells. Biol Chem, 384: 951-958

[53] Rollins BJ (1996). Monocyte chemoattractant protein 1: a potential regulator of monocyte recruitment in inflammatory disease. Mol Med Today, 2: 198-204

[54] Ma J, Wang Q, Fei T, Han JD, Chen YG (2007). MCP1 mediates TGF-beta-induced angiogenesis by stimulating vascular smooth muscle cell migration. Blood, 109: 987-994

[55] Rossi D, Zlotnik A (2000). The biology of chemokines and their receptors. Annu Rev Immunol, 18: 217-242 Salcedo R, Ponce ML, Young HA, Wasserman K, Ward JM, Kleinman HK, et al. (2000). Human endothelial cells express CCR2 and respond to MCP1: direct role of $\mathrm{MCP}-1$ in angiogenesis and tumor progression. Blood, 96: 34-40 
[57] Spinetti G, Wang M, Monticone R, Zhang J, Zhao D, Lakatta EG (2004). Rat aortic MCP-1 and its receptor CCR2 increase with age and alter vascular smooth muscle cell function. Arterioscler Thromb Vasc Biol, 24: 1397-1402

[58] Tsuchiya K, Yoshimoto T, Hirono Y, Tateno T, Sugiyama T, Hirata Y (2006). Angiotensin II induces monocyte chemoattractant protein-1 expression via a nuclear factor-kappaB-dependent pathway in rat preadipocytes. Am J Physiol Endocrinol Metab, 291: E771-E778

[59] Chen XL, Tummala PE, Olbrych MT, Alexander RW, Medford RM (1998). Angiotensin II induces monocyte chemoattractant protein-1 gene expression in rat vascular smooth muscle cells. Circ Res, 83: 952959

[60] Pohlers D, Brenmoehl J, Loffler I, Muller CK, Leipner C, Schultze-Mosgau S, et al. (2009). TGF-beta and fibrosis in different organs - molecular pathway imprints. Biochim Biophys Acta, 1792: 746-756

[61] Feng XH, Derynck R (2005). Specificity and versatility in tgf-beta signaling through Smads. Annu Rev Cell Dev Biol, 21: 659-693

[62] Nakao A, Afrakhte M, Moren A, Nakayama T, Christian JL, Heuchel R, et al. (1997). Identification of Smad7, a TGFbeta-inducible antagonist of TGFbeta signalling. Nature, 389: 631-635

[63] Weigert C, Brodbeck K, Klopfer K, Haring HU, Schleicher ED (2002). Angiotensin II induces human TGF-beta 1 promoter activation: similarity to hyperglycaemia. Diabetologia, 45: 890-898

[64] Yu Q, Stamenkovic I (2000). Cell surface-localized matrix metalloproteinase-9 proteolytically activates TGF-beta and promotes tumor invasion and angiogenesis. Genes Dev, 14: 163-176

[65] Wang M, Zhao D, Spinetti G, Zhang J, Jiang LQ, Pintus G, et al. (2006). Matrix metalloproteinase 2 activation of transforming growth factor-betal (TGFbeta1) and TGF-beta1-type II receptor signaling within the aged arterial wall. Arterioscler Thromb Vasc Biol, 26: 1503-1509

[66] Ying WZ, Aaron KJ, Sanders PW (2013). Transforming growth factor-beta regulates endothelial function during high salt intake in rats. Hypertension, 62: 951-956

[67] Fleenor BS, Marshall KD, Durrant JR, Lesniewski LA, Seals DR (2010). Arterial stiffening with ageing is associated with transforming growth factor-beta1related changes in adventitial collagen: reversal by aerobic exercise. J Physiol, 588: 3971-3982

[68] Fortuno A, San JG, Moreno MU, Diez J, Zalba G (2005). Oxidative stress and vascular remodelling. Exp Physiol, 90: 457-462

[69] Erusalimsky JD (2009). Vascular endothelial senescence: from mechanisms to pathophysiology. J Appl Physiol (1985), 106: 326-332

[70] Rajagopalan S, Kurz S, Munzel T, Tarpey M, Freeman BA, Griendling KK, et al. (1996). Angiotensin IImediated hypertension in the rat increases vascular superoxide production via membrane NADH/NADPH oxidase activation. Contribution to alterations of vasomotor tone. J Clin Invest, 97: 1916-1923

[71] Touyz RM (2003). Reactive oxygen species in vascular biology: role in arterial hypertension. Expert Rev Cardiovasc Ther, 1: 91-106

[72] Beckman JS (2001). -OONO: rebounding from nitric oxide. Circ Res, 89: 295-297

[73] Faraci FM, Didion SP (2004). Vascular protection: superoxide dismutase isoforms in the vessel wall. Arterioscler Thromb Vasc Biol, 24: 1367-1373

[74] Zhao H, Han Z, Ji X, Luo Y (2016). Epigenetic Regulation of Oxidative Stress in Ischemic Stroke. Aging Dis, 7: 295-306

[75] Guzik TJ, Mussa S, Gastaldi D, Sadowski J, Ratnatunga C, Pillai R, et al. (2002). Mechanisms of increased vascular superoxide production in human diabetes mellitus: role of $\mathrm{NAD}(\mathrm{P}) \mathrm{H}$ oxidase and endothelial nitric oxide synthase. Circulation, 105: 1656-1662

[76] Soucy KG, Ryoo S, Benjo A, Lim HK, Gupta G, Sohi JS, et al. (2006). Impaired shear stress-induced nitric oxide production through decreased NOS phosphorylation contributes to age-related vascular stiffness. J Appl Physiol (1985), 101: 1751-1759

[77] Nelson KK, Melendez JA (2004). Mitochondrial redox control of matrix metalloproteinases. Free Radic Biol Med, 37: 768-784

[78] Rajagopalan S, Meng XP, Ramasamy S, Harrison DG, Galis ZS (1996). Reactive oxygen species produced by macrophage-derived foam cells regulate the activity of vascular matrix metalloproteinases in vitro. Implications for atherosclerotic plaque stability. J Clin Invest, 98: 2572-2579

[79] Krishnan KJ, Greaves LC, Reeve AK, Turnbull DM (2007). Mitochondrial DNA mutations and aging. Ann N Y Acad Sci, 1100: 227-240

[80] Mecocci P, MacGarvey U, Kaufman AE, Koontz D, Shoffner JM, Wallace DC, et al. (1993). Oxidative damage to mitochondrial DNA shows marked agedependent increases in human brain. Ann Neurol, 34: 609-616

[81] Corral-Debrinski M, Horton T, Lott MT, Shoffner JM, Beal MF, Wallace DC (1992). Mitochondrial DNA deletions in human brain: regional variability and increase with advanced age. Nat Genet, 2: 324-329

[82] Pak JW, Vang F, Johnson C, McKenzie D, Aiken JM (2005). MtDNA point mutations are associated with deletion mutations in aged rat. Exp Gerontol, 40: 209218

[83] Larsson NG (2010). Somatic mitochondrial DNA mutations in mammalian aging. Annu Rev Biochem, 79: 683-706

[84] Clayton DA (1982). Replication of animal mitochondrial DNA. Cell, 28: 693-705

[85] Wenzel P, Schuhmacher S, Kienhofer J, Muller J, Hortmann M, Oelze M, et al. (2008). Manganese superoxide dismutase and aldehyde dehydrogenase deficiency increase mitochondrial oxidative stress and aggravate age-dependent vascular dysfunction. Cardiovasc Res, 80: 280-289 
[86] Ballinger SW, Patterson C, Yan CN, Doan R, Burow DL, Young CG, et al. (2000). Hydrogen peroxide- and peroxynitrite-induced mitochondrial DNA damage and dysfunction in vascular endothelial and smooth muscle cells. Circ Res, 86: 960-966

[87] Barja G, Herrero A (2000). Oxidative damage to mitochondrial DNA is inversely related to maximum life span in the heart and brain of mammals. Faseb J, 14: 312-318

[88] Aliev G, Gasimov E, Obrenovich ME, Fischbach K, Shenk JC, Smith MA, et al. (2008). Atherosclerotic lesions and mitochondria DNA deletions in brain microvessels: implication in the pathogenesis of Alzheimer's disease. Vasc Health Risk Manag, 4: 721730

[89] Bender A, Krishnan KJ, Morris CM, Taylor GA, Reeve AK, Perry RH, et al. (2006). High levels of mitochondrial DNA deletions in substantia nigra neurons in aging and Parkinson disease. Nat Genet, 38: 515-517

[90] Kim Y, Yoo JM, Jeon HR, Hong BH (2013). Efficient n-doping of graphene films by APPE (aminophenyl propargyl ether): a substituent effect. Phys Chem Chem Phys, 15: 18353-18356

[91] Banoei MM, Houshmand M, Panahi MS, Shariati P, Rostami M, Manshadi MD, et al. (2007). Huntington's disease and mitochondrial DNA deletions: event or regular mechanism for mutant huntingtin protein and CAG repeats expansion?!. Cell Mol Neurobiol, 27: 867-875

[92] Botto N, Berti S, Manfredi S, Al-Jabri A, Federici C, Clerico A, et al. (2005). Detection of mtDNA with 4977 bp deletion in blood cells and atherosclerotic lesions of patients with coronary artery disease. Mutat Res, 570: 81-88

[93] Yu E, Calvert PA, Mercer JR, Harrison J, Baker L, Figg NL, et al. (2013). Mitochondrial DNA damage can promote atherosclerosis independently of reactive oxygen species through effects on smooth muscle cells and monocytes and correlates with higher-risk plaques in humans. Circulation, 128: 702-712

[94] Roy AK, Lavrovsky Y, Song CS, Chen S, Jung MH, Velu NK, et al. (1999). Regulation of androgen action. Vitam Horm, 55: 309-352

[95] Foradori CD, Weiser MJ, Handa RJ (2008). Nongenomic actions of androgens. Front Neuroendocrinol, 29: 169-181

[96] Wu FC, von Eckardstein A (2003). Androgens and coronary artery disease. Endocr Rev, 24: 183-217

[97] Bhasin S, Buckwalter JG (2001). Testosterone supplementation in older men: a rational idea whose time has not yet come. J Androl, 22: 718-731

[98] Miller VM, Mulvagh SL (2007). Sex steroids and endothelial function: translating basic science to clinical practice. Trends Pharmacol Sci, 28: 263-270

[99] Yu J, Akishita M, Eto M, Ogawa S, Son BK, Kato S, et al. (2010). Androgen receptor-dependent activation of endothelial nitric oxide synthase in vascular endothelial cells: role of phosphatidylinositol 3kinase/akt pathway. Endocrinology, 151: 1822-1828
[100] Goglia L, Tosi V, Sanchez AM, Flamini MI, Fu XD, Zullino S, et al. (2010). Endothelial regulation of eNOS, PAI-1 and t-PA by testosterone and dihydrotestosterone in vitro and in vivo. Mol Hum Reprod, 16: 761-769

[101] Kelly DM, Jones TH (2013). Testosterone: a vascular hormone in health and disease. J Endocrinol, 217: R47-R71

[102] Akishita M, Hashimoto M, Ohike Y, Ogawa S, Iijima $\mathrm{K}$, Eto M, et al. (2007). Low testosterone level is an independent determinant of endothelial dysfunction in men. Hypertens Res, 30: 1029-1034

[103] Scragg JL, Jones RD, Channer KS, Jones TH, Peers C (2004). Testosterone is a potent inhibitor of L-type $\mathrm{Ca}(2+)$ channels. Biochem Biophys Res Commun, 318: 503-506

[104] Yildiz O, Seyrek M, Gul H, Un I, Yildirim V, Ozal E, et al. (2005). Testosterone relaxes human internal mammary artery in vitro. J Cardiovasc Pharmacol, 45: 580-585

[105] Marijic J, Li Q, Song M, Nishimaru K, Stefani E, Toro L (2001). Decreased expression of voltage- and $\mathrm{Ca}(2+)$-activated $\mathrm{K}(+)$ channels in coronary smooth muscle during aging. Circ Res, 88: 210-216

[106] Zhou P, Fu L, Pan Z, Ma D, Zhang Y, Qu F, et al. (2008). Testosterone deprivation by castration impairs expression of voltage-dependent potassium channels in rat aorta. Eur J Pharmacol, 593: 87-91

[107] Mathur A, Malkin C, Saeed B, Muthusamy R, Jones TH, Channer K (2009). Long-term benefits of testosterone replacement therapy on angina threshold and atheroma in men. Eur J Endocrinol, 161: 443-449

[108] Yaron M, Greenman Y, Rosenfeld JB, Izkhakov E, Limor R, Osher E, et al. (2009). Effect of testosterone replacement therapy on arterial stiffness in older hypogonadal men. Eur J Endocrinol, 160: 839-846

[109] Dockery F, Bulpitt CJ, Donaldson M, Fernandez S, Rajkumar C (2003). The relationship between androgens and arterial stiffness in older men. J Am Geriatr Soc, 51: 1627-1632

[110] English KM, Jones RD, Jones TH, Morice AH, Channer KS (2000). Aging reduces the responsiveness of coronary arteries from male Wistar rats to the vasodilatory action of testosterone. Clin Sci (Lond), 99: $77-82$

[111] Webb CM, McNeill JG, Hayward CS, de Zeigler D, Collins P (1999). Effects of testosterone on coronary vasomotor regulation in men with coronary heart disease. Circulation, 100: 1690-1696

[112] Jones RD, Pugh PJ, Jones TH, Channer KS (2003). The vasodilatory action of testosterone: a potassiumchannel opening or a calcium antagonistic action? $\mathrm{Br}$ J Pharmacol, 138: 733-744

[113] Kang SM, Jang Y, Kim J, Chung N, Cho SY, Chae JS, et al. (2002). Effect of oral administration of testosterone on brachial arterial vasoreactivity in men with coronary artery disease. Am J Cardiol, 89: 862864

[114] Yeap BB, Hyde Z, Almeida OP, Norman PE, Chubb SA, Jamrozik K, et al. (2009). Lower testosterone 
levels predict incident stroke and transient ischemic attack in older men. J Clin Endocrinol Metab, 94: 2353-2359

[115] Lv W, Du N, Liu Y, Fan X, Wang Y, Jia X, et al. (2016). Low Testosterone Level and Risk of Alzheimer's Disease in the Elderly Men: a Systematic Review and Meta-Analysis. Mol Neurobiol, 53: 26792684

[116] Huang G, Wharton W, Bhasin S, Harman SM, Pencina KM, Tsitouras P, et al. (2016). Effects of long-term testosterone administration on cognition in older men with low or low-to-normal testosterone concentrations: a prespecified secondary analysis of data from the randomised, double-blind, placebo-controlled TEAAM trial. Lancet Diabetes Endocrinol, 4: 657-665

[117] Jamadar RJ, Winters MJ, Maki PM (2012). Cognitive changes associated with ADT: a review of the literature. Asian J Androl, 14: 232-238

[118] Mendelsohn ME (2002). Protective effects of estrogen on the cardiovascular system. Am J Cardiol, 89: 12E17E, 17E-18E

[119] Hisamoto K, Ohmichi M, Kurachi H, Hayakawa J, Kanda Y, Nishio Y, et al. (2001). Estrogen induces the Akt-dependent activation of endothelial nitric-oxide synthase in vascular endothelial cells. J Biol Chem, 276: $3459-3467$

[120] Nakajima T, Kitazawa T, Hamada E, Hazama H, Omata M, Kurachi Y (1995). 17beta-Estradiol inhibits the voltage-dependent L-type Ca2+ currents in aortic smooth muscle cells. Eur J Pharmacol, 294: 625-635

[121] Novella S, Dantas AP, Segarra G, Medina P, Hermenegildo C (2012). Vascular Aging in Women: is Estrogen the Fountain of Youth? Front Physiol, 3: 165

[122] Wu Z, Maric C, Roesch DM, Zheng W, Verbalis JG, Sandberg K (2003). Estrogen regulates adrenal angiotensin AT1 receptors by modulating AT1 receptor translation. Endocrinology, 144: 3251-3261

[123] Hodis HN, Mack WJ, Henderson VW, Shoupe D, Budoff MJ, Hwang-Levine J, et al. (2016). Vascular Effects of Early versus Late Postmenopausal Treatment with Estradiol. N Engl J Med, 374: 12211231

[124] McCarrey AC, Resnick SM (2015). Postmenopausal hormone therapy and cognition. Horm Behav, 74: 167172

[125] Gleason CE, Dowling NM, Wharton W, Manson JE, Miller VM, Atwood CS, et al. (2015). Effects of Hormone Therapy on Cognition and Mood in Recently Postmenopausal Women: Findings from the Randomized, Controlled KEEPS-Cognitive and Affective Study. Plos Med, 12: e1001833, e1001833

[126] Robb AO, Mills NL, Din JN, Smith IB, Paterson F, Newby DE, et al. (2009). Influence of the menstrual cycle, pregnancy, and preeclampsia on arterial stiffness. Hypertension, 53: 952-958

[127] Williams MR, Westerman RA, Kingwell BA, Paige J, Blombery PA, Sudhir K, et al. (2001). Variations in endothelial function and arterial compliance during the menstrual cycle. J Clin Endocrinol Metab, 86:
5389-5395

[128] Zaydun G, Tomiyama H, Hashimoto H, Arai T, Koji Y, Yambe M, et al. (2006). Menopause is an independent factor augmenting the age-related increase in arterial stiffness in the early postmenopausal phase. Atherosclerosis, 184: 137-142

[129] Tang Y, Wang L, Wang J, Lin X, Wang Y, Jin K, et al. (2016). Ischemia-induced Angiogenesis is Attenuated in Aged Rats. Aging Dis, 7: 326-335

[130] Smulyan H, Asmar RG, Rudnicki A, London GM, Safar ME (2001). Comparative effects of aging in men and women on the properties of the arterial tree. J Am Coll Cardiol, 37: 1374-1380

[131] Takahashi K, Miura S, Mori-Abe A, Kawagoe J, Takata K, Ohmichi M, et al. (2005). Impact of menopause on the augmentation of arterial stiffness with aging. Gynecol Obstet Invest, 60: 162-166

[132] Ryan J, Scali J, Carriere I, Amieva H, Rouaud O, Berr $\mathrm{C}$, et al. (2014). Impact of a premature menopause on cognitive function in later life. BJOG, 121: 1729-1739

[133] Mitchell ES, Woods NF (2011). Cognitive symptoms during the menopausal transition and early postmenopause. Climacteric, 14: 252-261

[134] Henderson VW, Sherwin BB (2007). Surgical versus natural menopause: cognitive issues. Menopause, 14: $572-579$

[135] Henderson VW, Guthrie JR, Dudley EC, Burger HG, Dennerstein L (2003). Estrogen exposures and memory at midlife: a population-based study of women. Neurology, 60: 1369-1371

[136] Fuh JL, Wang SJ, Lee SJ, Lu SR, Juang KD (2006). A longitudinal study of cognition change during early menopausal transition in a rural community. Maturitas, 53: 447-453

[137] Greendale GA, Huang MH, Wight RG, Seeman T, Luetters C, Avis NE, et al. (2009). Effects of the menopause transition and hormone use on cognitive performance in midlife women. Neurology, 72: 18501857

[138] Franklin SS, Gustin WT, Wong ND, Larson MG, Weber MA, Kannel WB, et al. (1997). Hemodynamic patterns of age-related changes in blood pressure. The Framingham Heart Study. Circulation, 96: 308-315

[139] Franklin SS, Lopez VA, Wong ND, Mitchell GF, Larson MG, Vasan RS, et al. (2009). Single versus combined blood pressure components and risk for cardiovascular disease: the Framingham Heart Study. Circulation, 119: 243-250

[140] James MA, Watt PA, Potter JF, Thurston H, Swales JD (1995). Pulse pressure and resistance artery structure in the elderly. Hypertension, 26: 301-306

[141] Fernando MS, Simpson JE, Matthews F, Brayne C, Lewis CE, Barber R, et al. (2006). White matter lesions in an unselected cohort of the elderly: molecular pathology suggests origin from chronic hypoperfusion injury. Stroke, 37: 1391-1398

[142] Okamoto Y, Yamamoto T, Kalaria RN, Senzaki H, Maki T, Hase Y, et al. (2012). Cerebral hypoperfusion accelerates cerebral amyloid angiopathy and promotes cortical microinfarcts. Acta Neuropathol, 123: 381- 
394

[143] Luckhaus C, Flub MO, Wittsack HJ, Grass-Kapanke B, Janner M, Khalili-Amiri R, et al. (2008). Detection of changed regional cerebral blood flow in mild cognitive impairment and early Alzheimer's dementia by perfusion-weighted magnetic resonance imaging. Neuroimage, 40: 495-503

[144] Osawa A, Maeshima S, Shimamoto Y, Maeshima E, Sekiguchi E, Kakishita K, et al. (2004). Relationship between cognitive function and regional cerebral blood flow in different types of dementia. Disabil Rehabil, 26: 739-745

[145] Roman GC (2003). Vascular dementia: distinguishing characteristics, treatment, and prevention. J Am Geriatr Soc, 51: S296-S304

[146] Moorhouse P, Rockwood K (2008). Vascular cognitive impairment: current concepts and clinical developments. Lancet Neurol, 7: 246-255

[147] Hanon O, Haulon S, Lenoir H, Seux ML, Rigaud AS, Safar M, et al. (2005). Relationship between arterial stiffness and cognitive function in elderly subjects with complaints of memory loss. Stroke, 36: 21932197

[148] Calik AN, Ozcan KS, Yuksel G, Gungor B, Arugarslan E, Varlibas F, et al. (2014). Altered diastolic function and aortic stiffness in Alzheimer's disease. Clin Interv Aging, 9: 1115-1121

[149] Scuteri A, Tesauro M, Appolloni S, Preziosi F, Brancati AM, Volpe M (2007). Arterial stiffness as an independent predictor of longitudinal changes in cognitive function in the older individual. J Hypertens, 25: $1035-1040$

[150] Scuteri A, Brancati AM, Gianni W, Assisi A, Volpe M (2005). Arterial stiffness is an independent risk factor for cognitive impairment in the elderly: a pilot study. J Hypertens, 23: 1211-1216

[151] Rabkin SW, Jarvie G (2011). Comparison of vascular stiffness in vascular dementia, Alzheimer dementia and cognitive impairment. Blood Press, 20: 274-283

[152] Vendemiale G, Romano AD, Dagostino M, de Matthaeis A, Serviddio G (2013). Endothelial dysfunction associated with mild cognitive impairment in elderly population. Aging Clin Exp Res, 25: 247-255

[153] Hughes TM, Kuller LH, Barinas-Mitchell EJ, Mackey RH, McDade EM, Klunk WE, et al. (2013). Pulse wave velocity is associated with beta-amyloid deposition in the brains of very elderly adults. Neurology, 81: 1711-1718

[154] Hughes TM, Kuller LH, Barinas-Mitchell EJ, McDade EM, Klunk WE, Cohen AD, et al. (2014). Arterial stiffness and beta-amyloid progression in nondemented elderly adults. Jama Neurol, 71: 562568

[155] Qiu C, Winblad B, Viitanen M, Fratiglioni L (2003). Pulse pressure and risk of Alzheimer disease in persons aged 75 years and older: a community-based, longitudinal study. Stroke, 34: 594-599

[156] Nation DA, Edland SD, Bondi MW, Salmon DP, Delano-Wood L, Peskind ER, et al. (2013). Pulse pressure is associated with Alzheimer biomarkers in cognitively normal older adults. Neurology, 81: 20242027

[157] Nation DA, Edmonds EC, Bangen KJ, Delano-Wood L, Scanlon BK, Han SD, et al. (2015). Pulse pressure in relation to tau-mediated neurodegeneration, cerebral amyloidosis, and progression to dementia in very old adults. Jama Neurol, 72: 546-553

[158] Schuff N, Matsumoto S, Kmiecik J, Studholme C, Du A, Ezekiel F, et al. (2009). Cerebral blood flow in ischemic vascular dementia and Alzheimer's disease, measured by arterial spin-labeling magnetic resonance imaging. Alzheimers Dement, 5: 454-462

[159] Pase MP, Grima NA, Stough C, Scholey A, Pipingas A (2014). Association of pulsatile and mean cerebral blood flow velocity with age and neuropsychological performance. Physiol Behav, 130: 23-27

[160] Tarumi T, Ayaz KM, Liu J, Tseng BY, Parker R, Riley J, et al. (2014). Cerebral hemodynamics in normal aging: central artery stiffness, wave reflection, and pressure pulsatility. J Cereb Blood Flow Metab, 34: 971-978

[161] Liu H, Xing A, Wang X, Liu G, Li L (2012). Regulation of beta-amyloid level in the brain of rats with cerebrovascular hypoperfusion. Neurobiol Aging, 33: 826-831

[162] Niwa K, Porter VA, Kazama K, Cornfield D, Carlson GA, Iadecola C (2001). A beta-peptides enhance vasoconstriction in cerebral circulation. Am J Physiol Heart Circ Physiol, 281: H2417-H2424

[163] Price JM, Chi X, Hellermann G, Sutton ET (2001). Physiological levels of beta-amyloid induce cerebral vessel dysfunction and reduce endothelial nitric oxide production. Neurol Res, 23: 506-512

[164] Paris D, Humphrey J, Quadros A, Patel N, Crescentini R, Crawford F, et al. (2003). Vasoactive effects of A beta in isolated human cerebrovessels and in a transgenic mouse model of Alzheimer's disease: role of inflammation. Neurol Res, 25: 642-651

[165] Kim AS, Johnston SC (2013). Temporal and geographic trends in the global stroke epidemic. Stroke, 44: S123-S125

[166] Laurent S, Katsahian S, Fassot C, Tropeano AI, Gautier I, Laloux B, et al. (2003). Aortic stiffness is an independent predictor of fatal stroke in essential hypertension. Stroke, 34: 1203-1206

[167] Mattace-Raso FU, van der Cammen TJ, Hofman A, van Popele NM, Bos ML, Schalekamp MA, et al. (2006). Arterial stiffness and risk of coronary heart disease and stroke: the Rotterdam Study. Circulation, 113: $657-663$

[168] Willum-Hansen T, Staessen JA, Torp-Pedersen C, Rasmussen S, Thijs L, Ibsen H, et al. (2006). Prognostic value of aortic pulse wave velocity as index of arterial stiffness in the general population. Circulation, 113: 664-670

[169] van Sloten TT, Sedaghat S, Laurent S, London GM, Pannier B, Ikram MA, et al. (2015). Carotid stiffness is associated with incident stroke: a systematic review and individual participant data meta-analysis. J Am 
Coll Cardiol, 66: 2116-2125

[170] Gasecki D, Rojek A, Kwarciany M, Kubach M, Boutouyrie P, Nyka W, et al. (2012). Aortic stiffness predicts functional outcome in patients after ischemic stroke. Stroke, 43: 543-544

[171] Calvet D, Touze E, Laurent S, Varenne O, Sablayrolles JL, Boutouyrie P, et al. (2014). Aortic stiffness measurement improves the prediction of asymptomatic coronary artery disease in stroke/transient ischemic attack patients. Int J Stroke, 9: 291-296

[172] Seo WK, Lee JM, Park MH, Park KW, Lee DH (2008). Cerebral microbleeds are independently associated with arterial stiffness in stroke patients. Cerebrovasc Dis, 26: 618-623

[173] Blum A, Vaispapir V, Keinan-Boker L, Soboh S, Yehuda H, Tamir S (2012). Endothelial dysfunction and procoagulant activity in acute ischemic stroke. $\mathrm{J}$ Vasc Interv Neurol, 5: 33-39

[174] Chen PL, Wang PY, Sheu WH, Chen YT, Ho YP, Hu $\mathrm{HH}$, et al. (2006). Changes of brachial flow-mediated vasodilation in different ischemic stroke subtypes. Neurology, 67: 1056-1058

[175] Knottnerus IL, Ten CH, Lodder J, Kessels F, van Oostenbrugge RJ (2009). Endothelial dysfunction in lacunar stroke: a systematic review. Cerebrovasc Dis, 27: $519-526$

[176] Hassan A, Hunt BJ, O'Sullivan M, Parmar K, Bamford JM, Briley D, et al. (2003). Markers of endothelial dysfunction in lacunar infarction and ischaemic leukoaraiosis. Brain, 126: 424-432

[177] Hassan A, Gormley K, O'Sullivan M, Knight J, Sham P, Vallance P, et al. (2004). Endothelial nitric oxide gene haplotypes and risk of cerebral small-vessel disease. Stroke, 35: 654-659

[178] Wiseman S, Marlborough F, Doubal F, Webb DJ, Wardlaw J (2014). Blood markers of coagulation, fibrinolysis, endothelial dysfunction and inflammation in lacunar stroke versus non-lacunar stroke and nonstroke: systematic review and meta-analysis. Cerebrovasc Dis, 37: 64-75

[179] Deplanque D, Lavallee PC, Labreuche J, GongoraRivera F, Jaramillo A, Brenner D, et al. (2013). Cerebral and extracerebral vasoreactivity in symptomatic lacunar stroke patients: a case-control study. Int J Stroke, 8: 413-421

[180] Khan U, Porteous L, Hassan A, Markus HS (2007). Risk factor profile of cerebral small vessel disease and its subtypes. J Neurol Neurosurg Psychiatry, 78: 702706

[181] Wardlaw JM, Smith EE, Biessels GJ, Cordonnier C, Fazekas F, Frayne R, et al. (2013). Neuroimaging standards for research into small vessel disease and its contribution to ageing and neurodegeneration. Lancet Neurol, 12: 822-838

[182] Kalaria RN (2002). Small vessel disease and Alzheimer's dementia: pathological considerations. Cerebrovasc Dis, 13 Suppl 2: 48-52

[183] Yalcin A, Atmis V, Cengiz OK, Cinar E, Aras S, Varli M, et al. (2016). Evaluation of Cardiac Autonomic
Functions in Older Parkinson's Disease Patients: a Cross-Sectional Study. Aging Dis, 7: 28-35

[184] Kuo HK, Chen CY, Liu HM, Yen CJ, Chang KJ, Chang CC, et al. (2010). Metabolic risks, white matter hyperintensities, and arterial stiffness in highfunctioning healthy adults. Int J Cardiol, 143: 184-191 [185] Hatanaka R, Obara T, Watabe D, Ishikawa T, Kondo T, Ishikura K, et al. (2011). Association of arterial stiffness with silent cerebrovascular lesions: the Ohasama study. Cerebrovasc Dis, 31: 329-337

[186] Matsumoto M, Inoue K, Moriki A (2007). Associations of brachial-ankle pulse wave velocity and carotid atherosclerotic lesions with silent cerebral lesions. Hypertens Res, 30: 767-773

[187] Ochi N, Tabara Y, Igase M, Nagai T, Kido T, Miki T, et al. (2009). Silent cerebral microbleeds associated with arterial stiffness in an apparently healthy subject. Hypertens Res, 32: 255-260

[188] Poels MM, Zaccai K, Verwoert GC, Vernooij MW, Hofman A, van der Lugt A, et al. (2012). Arterial stiffness and cerebral small vessel disease: the Rotterdam Scan Study. Stroke, 43: 2637-2642

[189] van Elderen SG, Brandts A, Westenberg JJ, van der Grond J, Tamsma JT, van Buchem MA, et al. (2010). Aortic stiffness is associated with cardiac function and cerebral small vessel disease in patients with type 1 diabetes mellitus: assessment by magnetic resonance imaging. Eur Radiol, 20: 1132-1138

[190] Brisset M, Boutouyrie P, Pico F, Zhu Y, Zureik M, Schilling S, et al. (2013). Large-vessel correlates of cerebral small-vessel disease. Neurology, 80: 662-669 Hashimoto J, Aikawa T, Imai Y (2008). Large artery stiffening as a link between cerebral lacunar infarction and renal albuminuria. Am J Hypertens, 21: 13041309

[192] Ochi N, Kohara K, Tabara Y, Nagai T, Kido T, Uetani E, et al. (2010). Association of central systolic blood pressure with intracerebral small vessel disease in Japanese. Am J Hypertens, 23: 889-894

[193] Mitchell GF, van Buchem MA, Sigurdsson S, Gotal JD, Jonsdottir MK, Kjartansson O, et al. (2011). Arterial stiffness, pressure and flow pulsatility and brain structure and function: the Age, Gene/Environment Susceptibility--Reykjavik study. Brain, 134: 3398-3407

[194] Tsao CW, Seshadri S, Beiser AS, Westwood AJ, Decarli C, Au R, et al. (2013). Relations of arterial stiffness and endothelial function to brain aging in the community. Neurology, 81: 984-991

[195] Jochemsen HM, Muller M, Bots ML, Scheltens P, Vincken KL, Mali WP, et al. (2015). Arterial stiffness and progression of structural brain changes: The SMART-MR study. Neurology, 84: 448-455

[196] Marshall RS (2012). Effects of altered cerebral hemodynamics on cognitive function. J Alzheimers Dis, 32: 633-642

[197] Jellinger KA (2013). Pathology and pathogenesis of vascular cognitive impairment-a critical update. Front Aging Neurosci, 5: 17

[198] Webb AJ, Simoni M, Mazzucco S, Kuker W, Schulz 
U, Rothwell PM (2012). Increased cerebral arterial pulsatility in patients with leukoaraiosis: arterial stiffness enhances transmission of aortic pulsatility. Stroke, 43: 2631-2636

[199] Ding J, Mitchell GF, Bots ML, Sigurdsson S, Harris TB, Garcia M, et al. (2015). Carotid arterial stiffness and risk of incident cerebral microbleeds in older people: the Age, Gene/Environment Susceptibility (AGES)-Reykjavik study. Arterioscler Thromb Vasc Biol, 35: 1889-1895

[200] Akinyemi RO, Mukaetova-Ladinska EB, Attems J, Ihara M, Kalaria RN (2013). Vascular risk factors and neurodegeneration in ageing related dementias: Alzheimer's disease and vascular dementia. Curr Alzheimer Res, 10: 642-653

[201] Laurent S, Cockcroft J, Van Bortel L, Boutouyrie P, Giannattasio C, Hayoz D, et al. (2006). Expert consensus document on arterial stiffness: methodological issues and clinical applications. Eur Heart J, 27: 2588-2605

[202] Yu WC, Chuang SY, Lin YP, Chen CH (2008). Brachial-ankle vs carotid-femoral pulse wave velocity as a determinant of cardiovascular structure and function. J Hum Hypertens, 22: 24-31

[203] Wentland AL, Grist TM, Wieben O (2014). Review of MRI-based measurements of pulse wave velocity: a biomarker of arterial stiffness. Cardiovasc Diagn Ther, 4: 193-206

[204] Kuvin JT, Patel AR, Sliney KA, Pandian NG, Sheffy J, Schnall RP, et al. (2003). Assessment of peripheral vascular endothelial function with finger arterial pulse wave amplitude. Am Heart J, 146: 168-174

[205] Bullitt E, Rahman FN, Smith JK, Kim E, Zeng D, Katz LM, et al. (2009). The effect of exercise on the cerebral vasculature of healthy aged subjects as visualized by MR angiography. AJNR Am J Neuroradiol, 30: 1857-1863

[206] Bolduc V, Thorin-Trescases N, Thorin E (2013). Endothelium-dependent control of cerebrovascular functions through age: exercise for healthy cerebrovascular aging. Am J Physiol Heart Circ Physiol, 305: H620-H633

[207] Viboolvorakul S, Patumraj S (2014). Exercise training could improve age-related changes in cerebral blood flow and capillary vascularity through the upregulation of VEGF and eNOS. Biomed Res Int, 2014: 230791

[208] Rippe C, Lesniewski L, Connell M, LaRocca T, Donato A, Seals D (2010). Short-term calorie restriction reverses vascular endothelial dysfunction in old mice by increasing nitric oxide and reducing oxidative stress. Aging Cell, 9: 304-312

[209] Meyer TE, Kovacs SJ, Ehsani AA, Klein S, Holloszy JO, Fontana L (2006). Long-term caloric restriction ameliorates the decline in diastolic function in humans. J Am Coll Cardiol, 47: 398-402

[210] Laufs U, La Fata V, Plutzky J, Liao JK (1998). Upregulation of endothelial nitric oxide synthase by HMG CoA reductase inhibitors. Circulation, 97: 11291135

[211] Matsuo T, Iwade K, Hirata N, Yamashita M, Ikegami H, Tanaka N, et al. (2005). Improvement of arterial stiffness by the antioxidant and anti-inflammatory effects of short-term statin therapy in patients with hypercholesterolemia. Heart Vessels, 20: 8-12

[212] Lahera V, Goicoechea M, de Vinuesa SG, Miana M, de Las HN, Cachofeiro V, et al. (2007). Endothelial dysfunction, oxidative stress and inflammation in atherosclerosis: beneficial effects of statins. Curr Med Chem, 14: 243-248

[213] Mahmud A, Feely J (2004). Arterial stiffness and the renin-angiotensin-aldosterone system. J Renin Angiotensin Aldosterone Syst, 5: 102-108

[214] Ito T, Yamakawa H, Bregonzio C, Terron JA, FalconNeri A, Saavedra JM (2002). Protection against ischemia and improvement of cerebral blood flow in genetically hypertensive rats by chronic pretreatment with an angiotensin II AT1 antagonist. Stroke, 33: 2297-2303 